\title{
A Computational Model of Melt Pool Morphology for Selective Laser Melting Process
}

\author{
Kai Guo \\ Beihang University \\ Lihong Qiao \\ Beihang University \\ Zhicheng Huang ( $\nabla$ zc_huang@buaa.edu.cn ) \\ Beihang University \\ Nabil Anwer \\ Université Paris-Sud, Université Paris-Saclay \\ Yuda Cao \\ Beihang University
}

\section{Research Article}

Keywords: Selective laser melting, Geometrical shape simulation, Melt pool structure, Melt pool status, Computational model

Posted Date: November 2nd, 2021

DOI: https://doi.org/10.21203/rs.3.rs-1028151/v1

License: (c) (i) This work is licensed under a Creative Commons Attribution 4.0 International License.

Read Full License 


\title{
A computational model of melt pool morphology for
}

\section{selective laser melting process}

\author{
Kai Guo ${ }^{1}$, Lihong Qiao ${ }^{1}$, Zhicheng Huang ${ }^{*}$, Nabil Anwer ${ }^{2}$, Yuda Cao ${ }^{1}$ \\ ${ }^{1}$ Department of Industrial and Manufacturing Systems Engineering, Beihang \\ University, Beijing 100191, China \\ ${ }^{2}$ LURPA, ENS Paris-Saclay, Université Paris-Sud, Université Paris-Saclay, \\ 94235 Cachan, France
}

*Corresponding author. E-mail: zc_huang@buaa.edu.cn

\begin{abstract}
Selective laser melting (SLM) is a promising metal additive manufacturing technology, which holds widespread applications in numerous fields. Unfortunately, it is arduous to predict the real SLM part geometry, which impedes its further development. While the morphology of melt pool, influenced and determined by process parameters, poses a crucial influence on the overall part geometry. Nonetheless, the association between process parameters and melt pool morphology is still unclear. Hence it is indispensable to explore relevant solution to address this issue. For this purpose, this paper proposes a new model to directly establish the mathematical relationship between process parameters and melt pool structure for SLM process. In this model, the status of melt pool is first qualitatively analyzed via the defined synthetic process index, and three types of melting states are differentiated including low melting, intermediate melting and high melting, which could cover different melt pool modes. Then, the computational model involving more physical mechanisms integrating mass conversion, heat exchange and temperature field is constructed. Melt pool critical geometries including the height, width, depth and length could be computed through the model. In order to validate the correctness of the proposed model, published experimental observations and existing models are compared. Calculation results from the proposed model show high consistency with the experimental samples and better accuracy than existing empirical models. Its applicability in melt pool classification and prediction is also verified, laying foundation for geometric simulation of SLM object which is successively shaped melt-pool by melt-pool.
\end{abstract}

Keywords: Selective laser melting, Geometrical shape simulation, Melt pool structure, Melt pool status, Computational model 


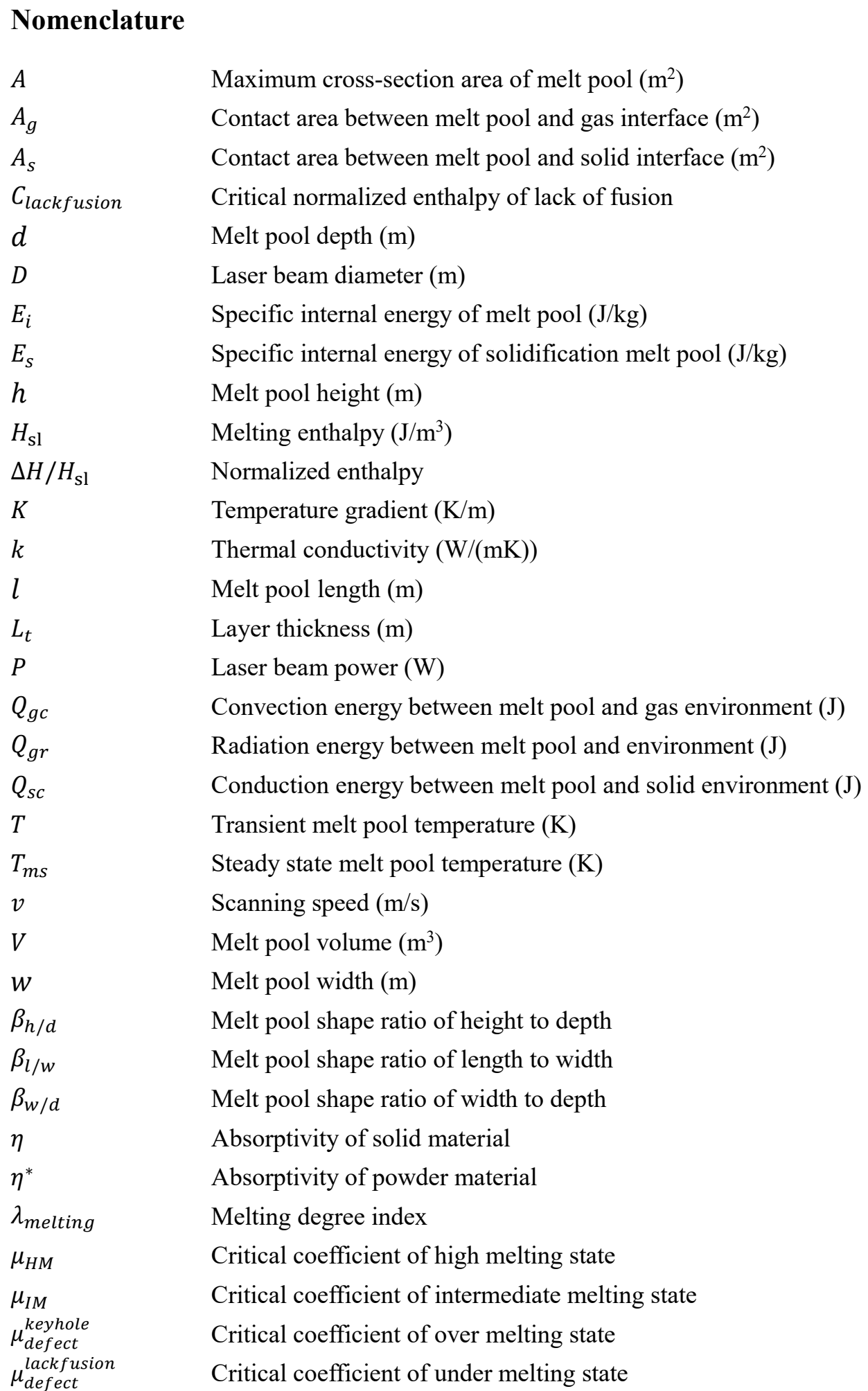

\section{Introduction}

Selective laser melting (SLM) or laser powder bed fusion (LPBF) is a potential metal additive manufacturing process $[1,2]$. However, it is formidable to predict the actual geometry of the deposited part, which is a bottleneck issue of this technology [3, 
4]. There are a multitude of contributors affecting the additive and layer-by-layer formed part geometry, while melt pool plays a direct and significant role in it $[5,6]$. Defective melt pools are likely to result in unqualified parts, and even lead to manufacture failure.

Melt pool geometry is a key indicator reflecting the SLM process quality. And melt pool shape was normally assumed as paraboloid [7] or semi-ellipsoid [8-10], which could represent certain characteristics of melt pool morphology. Typically, the real melt pool primarily consists of two portions as shown in Fig.1, where one is the newly deposited portion above the build surface and the other is the remelted portion in previously deposited layers or substrate. Essential dimensions of melt pool could briefly and approximately represent the overall shape characteristics of melt pool. The critical dimensions of melt pool consist the height, depth, width and length. For instance, the fluctuation of melt pool height may result in uneven or discontinuous build surface, which perhaps impedes the movement of scraper, inducing production accidents. When melt pool depth is excessively shallow, the physical bonding of material would be impaired, and the part cracks may appear. When melt pool depth is too deep, severe keyhole phenomenon will occur, which could cause the porosity defect. Besides, melt pool mode identification of conduction and keyhole could be measured by the ratio of melt pool width to depth $[11,12]$.

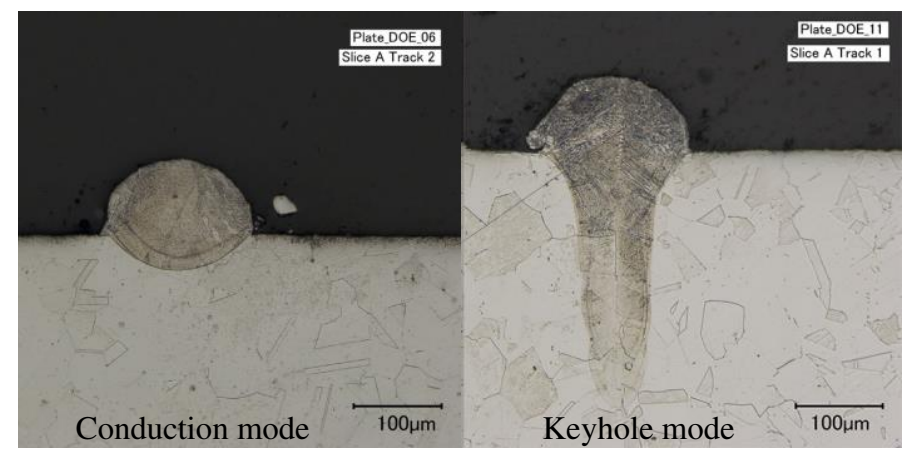

Fig.1 Metallographic cross sections of real melt pools adapted from [1]

Process parameters like laser beam power, scanning speed, laser beam size, layer thickness, etc. have a significant influence on melt pool morphology in SLM process $[1,13]$. Excessively high energy input brought about from process parameter combinations will lead to overheating defects, such as severe keyhole or keyhole porosity. On the contrary, excessively low energy input will give rise to underheating faults, like lack of fusion (incomplete fusion) or balling phenomenon. However, the link between melt pool morphologies and process parameters is unclear, thus it is awfully difficult to control the geometric quality of SLM products.

Efforts have been conducted to cope with the mentioned challenge in several aspects, including melt pool classification, synthetic process parameter index definition, and melt pool geometry calculation.

Some work on melt pool classification has been conducted. Scime and Beith [11] investigated the relation trend of melt pool width, depth and cross section area with 
process parameters for IN718 material in SLM process by experimental technique. According to geometric characteristics, the melt pools were classified into five categories as shown in Fig.2: desirable, balling, under-melting, severe keyholing and keyholing porosity. Francis [14] found that laser beam diameter significantly affects the shape and mode of melt pool. And melt pool morphologies were divided into four kinds: good, keyholing, under-melting and bead up. And the above mentioned classifications for melt pool are obtained based on experimental observations and measurements.

(a)

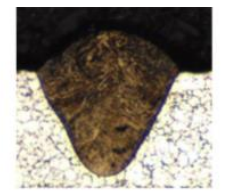

(d)

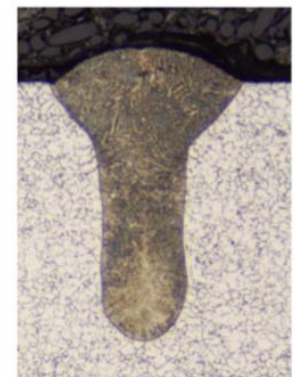

(b)

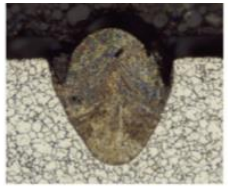

(c)

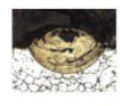

(e)

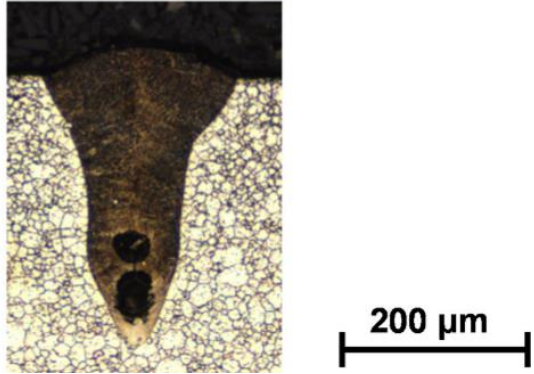

Fig.2 Representative micrographs of cross-section melt pools from [11] (a) Desirable (b) Balling (c) Under-melting (d) Severe keyholing (e) Keyholing porosity

Some synthetic process parameter indexes have been introduced to depict the melt pool characteristics. Bertoli et al. [15] adopted the volume energy density (VED) to character melt pool appearance. Experimental outcomes proved that VED could not sufficiently or effectively evaluate the melt pool structure. The VED considers the energy input but neglects the energy loss and conversion process. Accordingly, VED is unable to assess the melt pool morphology adequately. In comparison, normalized enthalpy (NE) could distinguish the melt pool mode transition between conduction and keyhole. Actually, Rubenchik et al. [1] utilized NE to differentiate melt pool modes, and gave the judgment criterion for keyhole mode. NE involves laser energy, scanning speed and laser beam diameter, which could determine the melt pool mode for $316 \mathrm{~L}$ material effectually. Nonetheless, the quantitative characteristics of melt pool structure cannot be revealed via NE.

Supposing that experimental technique was employed to investigate the bond of melt pool morphologies and process parameters, a vast number of experiments and measurements need to be carried out for distinct equipment, materials and process combinations, which is time-consuming and cost-consuming $[3,16]$. The computational or analytical model based on physical mechanism can be utilized with high calculation efficiency and cost-saving, and meanwhile could cut down trial-anderror experiment times [17]. Thus it is a reliable and feasible way to establish the association between melt pool structure and process parameters based on the physical principles during melt pool formation for SLM.

Tang et al. [18] utilized an experimental approach and analytical model to research 
the cross section of melt pool in SLM process. Promopatum et al. [19] calculated the melt pool width by Rosenthal analytical approach and finite element technique, and pointed out that Rosenthal analytical equation is feasible for low energy density conditions. Eagar and Tsai [20] established an analytical model of thermal field, which could be used to estimate some melt pool sizes. Wang et al. [8] adopted the heat transfer equation to derive the mathematical mapping relation between cross section area of melt pool and process parameters such as laser beam power and scanning speed.

However, the above mentioned empirical or analytical or finite element models were derived mainly from the mechanism of temperature field alone, without involving more material or energy transfer process. As a result, the above empirical models hold relatively poorer calculation accuracy for melt pool geometries. In addition, not all melt pool critical dimensions can be calculated through the above models, and the significant height characteristic of melt pool was ignored. Only regular structure of melt pool under narrow process parameter condition was investigated in most studies.

To address the above issues, a novel relevance model between process parameters and melt pool structure is constructed considering more physical mechanisms integrating mass conversion, heat exchange and temperature field theories to improve melt pool geometry calculation accuracy. The critical melt pool geometries including height (which is ignored by many studies), width, depth and length are involved. Melt pool modes of conduction and keyhole, and melt pool morphologies of normal and defective are considered.

In this study, a preliminary qualitative evaluation of melting states covering different modes for melt pools is first conducted utilizing the defined process parameter index. Afterwards, the mathematical relation between melt pool morphology and process parameters is established for different melting states based on physical mechanisms including the melt pool energy conservation, mass exchange and temperature field principles. Then melt pool structure could be calculated by process parameters through the developed model. A considerable experimental data sets of melt pool for distinct materials, machines and process parameters reported from literature are employed for comparative verification of its feasibility and robustness. Additionally, to further verify its effectiveness, the proposed model is contrasted with other existing empirical models. The applicability of the model in melt pool classification and prediction is also elaborated. The model could effectively and rapidly compute the pivotal morphological dimensions of melt pool, further reconstruct melt pool shape, and meanwhile reduce experimental trial-and-error costs, which provides potential use for melt pool defect identification and geometry simulation for the virtually SLM printed part which is cumulatively formed by melt pools. 


\section{The calculation model building}

\subsection{Qualitative evaluation of melt pool status}

To analyze melt pool structure, regular melt pool morphology needs to be considered, while the defective one should also be poured attention. Melt pool defects mainly contain under melting and over melting types. Under melting faults comprise balling effect, bead up and lack of fusion and so forth. Over melting flaws consist of severe keyhole, keyhole porosity, etc. The melting degree and working mode of melt pool play a fundamental role in melt pool morphology. Actually, to characterize the melting degree of melt pool, lack of fusion index (LF) was defined by Mukherjee et al. [21]. However, the LF index is represented as the ratio of melt pool depth to layer thickness, requiring to know the melt pool depth antecedently. Thus the LF index is limited to employ without certain melt pool results.

The melting states of melt pool are closely relevant to process parameters. They could be assessed depending on process factors such as laser beam power, scanning speed, laser diameter and layer thickness, etc. Normalized Enthalpy (NE) could be adopted to evaluate the working mode of melt pool $[15,22]$, and the expression of NE is shown in Formula (1):

$$
\frac{\Delta H}{H_{\mathrm{sl}}}=\frac{\eta P}{\pi H_{\mathrm{sl}} \sqrt{a v D^{3}}}
$$

Where $\eta$ : laser absorptivity of material, $P$ : laser beam power, $H_{\mathrm{sl}}$ : melting enthalpy, $a$ : thermal diffusion coefficient, $v$ : scanning speed and $D$ : laser beam diameter.

When the material is just completely melted, the volume energy density could be expressed as Formula (2):

$$
\frac{\eta P}{v D L_{t}}=H_{\mathrm{sl}}+\rho C\left(T_{m}-T_{o}\right)
$$

The left side of Equation (2) denotes the volume energy density, while the right side denotes the minimum energy required to melt the material per volume. Where $H_{\mathrm{sl}}$ is the melting enthalpy per volume, and $\rho C\left(T_{m}-T_{o}\right)$ accounts for heat capacity of the material from initial temperature to the melting temperature.

To assess melting degree of melt pool, the critical normalized enthalpy of lack of fusion could be defined and signified as $C_{\text {lackfusion }}$ when the material has just melted completely. By introducing Formula (2) into Formula (1), the critical normalized enthalpy for melting the material can be obtained, and the representation of which is shown in Formula (3):

$$
C_{\text {lackfusion }}=\frac{v L_{t}\left(h_{\mathrm{sl}}+C\left(T_{m}-T_{o}\right)\right)}{\pi h_{\mathrm{sl}} \sqrt{\operatorname{avD}}}
$$

Where $v$ : scanning speed, $L_{t}$ : layer thickness, $h_{\mathrm{sl}}$ : melting enthalpy per mass $\left(H_{\mathrm{sl}}=\rho h_{\mathrm{sl}}\right), C:$ material specific heat capacity, $T_{m}$ : melting temperature of material, $T_{o}$ : initial temperature of material, $a$ : thermal diffusion coefficient, $D$ : laser beam 
diameter, $\rho$ : material density.

To analyze different melt pool morphologies and quantificationally distinguish the melting degree of melt pool, the proportion of NE to $C_{\text {lackfusion }}$ is defined as melting degree index ( $\left.\lambda_{\text {melting }}\right)$, as shown in Formula (4).

$$
\lambda_{\text {melting }}=\frac{\Delta H}{H_{\mathrm{sl}}} / C_{\text {lackfusion }}
$$

According to the melting degree index, melt pool melting states could be divided into three categories: i) low melting (LM); ii) intermediate melting (IM); iii) high melting (HM). Normal and defective melt pool morphologies may arise under the proposed three kinds of melting states. By contrast, it is more probable to appear defective melt pools in LM and HM states. Generally, the melt pools under LM and HM states are prone to act in the conduction and keyhole mode correspondingly, whereas the IM melt pool might display in conduction or keyhole mode.

The parameters $\mu_{I M}$ and $\mu_{H M}$ are adopted as bounds to differentiate the melt pool melting states, wherein $\mu_{H M}>\mu_{I M}>1$. The coefficients $\mu_{\text {defect }}^{\text {lackfion }}$ and $\mu_{\text {defect }}^{\text {keyhole }}$ are adopted to estimate whether the melt pool appears under melting or over melting defects respectively. Under melting phenomenon occurs typically in LM state, while over melting defect frequently emerges in HM state.

The melting state and morphology character of melt pool could be analyzed according to the above defined synthetic index of process parameters as shown in Fig.3. The criteria for evaluating the melt pool status and morphology attributes are as follows:

1) Low melting state: When $\lambda_{\text {melting }}<\mu_{I M}$, the melt pool is identified into LM state, and under melting defects such as balling effect and lack of fusion would probably appear during LM state specifically if $\lambda_{\text {melting }} \leq \mu_{\text {defect }}^{\text {lackfus }}$.

2) Intermediate melting state: When $\mu_{I M} \leq \lambda_{\text {melting }}<\mu_{H M}$, the melt pool is identified into IM state. When laser energy is appropriate, for example laser beam power matches the scanning speed properly, it is not prone to exhibit apparent melt pool defects.

3) High melting state: When $\lambda_{\text {melting }} \geq \mu_{H M}$, the melt pool is identified into HM state, and it is probable to form over melting faults, for instance serious keyhole and keyhole porosity, particularly if $\lambda_{\text {melting }} \geq \mu_{\text {defect }}^{\text {keyhole }}$.

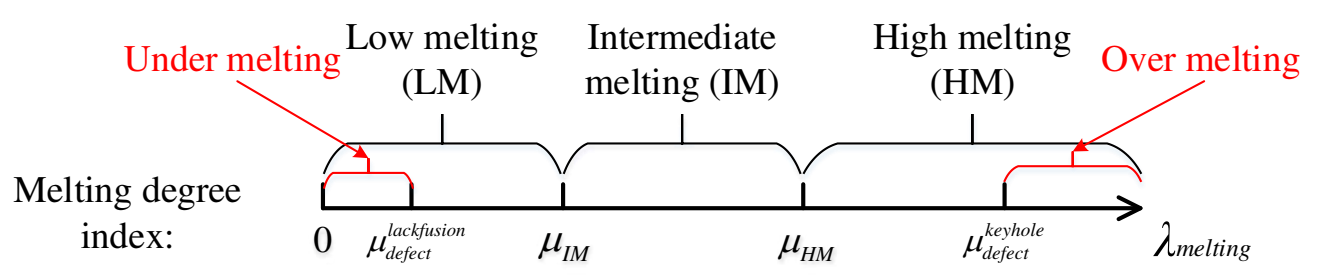

Fig.3 Analysis of melt pool status based on the defined synthetic index of process parameters

The preliminarily qualitative analysis of melt pool can be conducted through process parameters and material properties based on the above criteria. Three kinds of melting states of melt pool could be identified relying on the process parameters and material information. The parameters, including $\mu_{I M}, \mu_{H M}, \mu_{\text {defect }}^{\text {lackfusion }}$ and $\mu_{\text {defect }}^{\text {keyhole }}$, 
should be determined while analyzing the melting status of melt pool. Determination of the above parameters requires certain prior knowledge and experience, and could be conducted according to SLM equipment set-ups, material properties and experimental or simulation outcomes. Generally, their values would change as material or process condition varies. These threshold coefficients for different materials could be determined according to experimental results and experience, summarized as shown in Formulae (5)-(8):

$$
\begin{gathered}
\mu_{H M}=\chi^{m} \sqrt{\pi} T_{b} /\left(T_{m} C_{\text {lackfusion }}\right) \\
\mu_{I M}=\chi^{m} \pi \sqrt{\pi} / 2 C_{\text {lackfusion }} \\
\mu_{\text {defecte }}^{\text {keect }}=\Pi_{1}^{m} \mu_{H M} \\
\mu_{\text {deffect }}^{\text {lackion }}=\Pi_{2}^{m} \mu_{I M}
\end{gathered}
$$

Where $\chi^{m}$ : melting degree critical coefficient of material for differentiating the melting status including LM, IM and $\mathrm{HM}, \Pi_{1}^{m}$ : critical coefficient of material for over melting defect state $\left(\Pi_{1}^{m}>1\right), \Pi_{2}^{m}$ : critical coefficient of material for under melting defect state $\left(\Pi_{2}^{m}<1\right)$. The superscript $m$ represents the specific material type, such as Inconel 718 (IN718), Ti6A14V (TC4), SS316L (316L), etc. And the adopted values of these coefficients for some materials are given in Table 1.

Table 1 Adopted values of critical coefficients of melting status for different materials

\begin{tabular}{cccc}
\hline \multirow{2}{*}{ Material type } & \multicolumn{3}{c}{ Critical coefficients } \\
\cline { 2 - 4 } & $\chi^{m}$ & $\Pi_{1}^{m}$ & $\Pi_{2}^{m}$ \\
\hline IN718 & 2.2 & 1.3 & 0.7 \\
TC4 & 4 & 1.2 & 0.4 \\
316L & 2 & 2.5 & 0.7 \\
\hline
\end{tabular}

Normal and defective melt pool morphology could be roughly estimated through the above identified melting states. Furthermore, with the aim to quantitatively evaluate the structure of melt pool, more mechanisms and factors of melt pool formation should be considered and addressed.

\subsection{Quantitative calculation model of melt pool morphology}

\subsubsection{Critical melt pool geometry calculation}

The schematic diagram of melt pool energy exchange in SLM process is shown in Fig.4. The energy conversion process during melt tool formation involves powder melting, melt pool solidification, heat conduction between melt pool surface and baseplate (substrate or solidified layers), heat convection and radiation behaviors between melt pool surface and surrounding environment. 


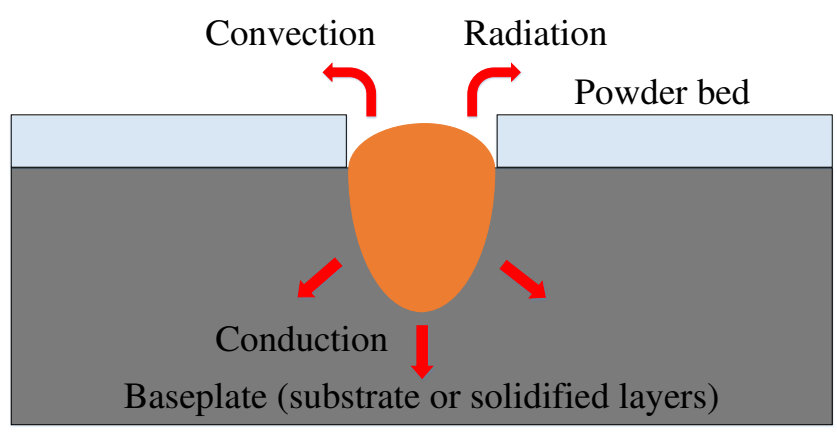

Fig.4 Schematic of melt pool energy exchange for SLM process

It is assumed that the material of substrate is the same as the powder. And the material properties such as density, specific heat capacity, thermal conductivity and thermal diffusivity are assumed to be constant. The melt pool formation process satisfies the differential equation of energy conservation as shown in Formula (9) [8].

$$
\frac{\mathrm{d}}{\mathrm{d} t}\left(\rho V(t) E_{i}(t)\right)+\rho A(t) v E_{s}+Q_{s c}+Q_{g c}+Q_{g r}-\eta^{*} P=0
$$

Where $V(t)$ and $A(t)$ indicate the volume and maximum cross section area of melt pool; $E_{i}(t)$ and $E_{s}$ represent the liquid and solidification specific internal energy of melt pool; $Q_{s c}$ denotes the thermal conduction between melt pool and baseplate, $Q_{g c}$ denotes the thermal convective between melt pool and the surrounding gas environment, and $Q_{g r}$ denotes the thermal radiation between melt pool and surrounding environment; $\eta^{*}$ denotes the energy absorptivity of powder material.

Specific internal energy of melt pool can be expressed as $E_{i}=C_{s}\left(T_{m}-T_{o}\right)+h_{\mathrm{sl}}+$ $C_{l}\left(T-T_{m}\right)$, and specific internal energy of solidification melt pool could be expressed as $E_{s}=C_{s}\left(T_{m}-T_{o}\right)$. Where $h_{\mathrm{sl}}$ denotes the melting latent heat, $T$ denotes the transient temperature of melt pool, $C_{S}$ and $C_{l}$ denote solid and liquid material specific heat respectively.

Due to the thermal conductivity of powder is much lower than that of solid material, the thermal conductivity between melt pool and powder bed is ignored [23]. The heat conduction between melt pool and build surface could be equivalent to heat convection [9]. Heat conduction between melt pool and build surface is represented as $Q_{s c}=$ $A_{s} \alpha_{s}\left(T-T_{o}\right)$. Where $A_{s}$ denotes the contact area between melt pool and solid interface, $\alpha_{s}$ denotes the equivalent convection coefficient. Assuming that the temperature gradient at the solid-liquid interface is uniform in all directions, the equivalent convection coefficient could be represented as $\alpha_{s}=2 \mathrm{kK} /\left(T_{b}+T_{m}\right)$, where interface temperature gradient $K=\left(T_{b}-T_{o}\right) \sqrt{v} \exp \left(-\operatorname{erfcinv}^{2}\left(\left(T_{m}-T_{o}\right) /\left(T_{b}-T_{o}\right)\right) / \sqrt{a \pi D}\right.$ [24], $k$ denotes the thermal conductivity.

Convective heat transfer between melt pool and surrounding gas environment is represented as $Q_{g c}=A_{g} \alpha_{g}\left(T-T_{o}\right)$. Where $A_{g}$ denotes the contact area between melt pool and gas interface, $\alpha_{g}$ denotes the convection coefficient of gas interface. Radiation heat conversion between melt pool and surrounding environment is expressed as $Q_{g r}=A_{g} \varepsilon \sigma\left(T^{4}-T_{o}^{4}\right)$. Where $\varepsilon$ denotes the radiation coefficient, and $\sigma$ denotes Stefan Boltzmann constant. 
According to the realistic shape of melt pool in SLM process, supposing that the melt pool was composed of two semi-ellipsoid shapes as shown in Fig.5. The assumed geometry could approximate a variety of real melt pools, and greatly simplifies analytical treatment. The critical geometry parameters of melt pool morphology consist of the width, height, depth and length. The shape of melt pool could be restructured through the critical melt pool geometric dimensions.

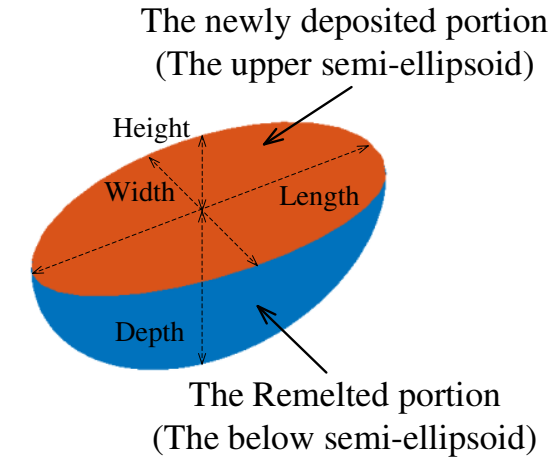

(a)

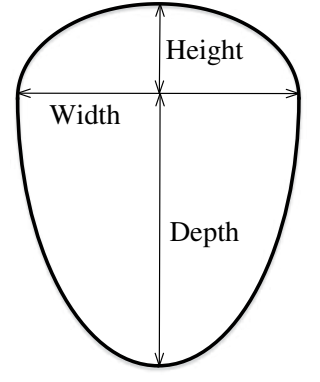

(b)

Fig.5 Schematic of melt pool morphology (a) 3D shape (b) 2D cross-section shape

The 3D geometry of melt pool could be restructured by the Equation (10), while 2D cross-section shape can be rebuilt via the Equation (11) approximately based on above geometric hypothesis.

$$
\begin{gathered}
\left\{\begin{array}{c}
\frac{4\left(x-x_{c}\right)^{2}}{l^{2}}+\frac{4\left(y-y_{c}\right)^{2}}{w^{2}}+\frac{\left(z-z_{c}\right)^{2}}{h^{2}}=1(z \geq 0) \\
\frac{4\left(x-x_{c}\right)^{2}}{l^{2}}+\frac{4\left(y-y_{c}\right)^{2}}{w^{2}}+\frac{\left(z-z_{c}\right)^{2}}{d^{2}}=1(z<0)
\end{array}\right. \\
\left\{\begin{array}{l}
\frac{4\left(y-y_{c}\right)^{2}}{w^{2}}+\frac{\left(z-z_{c}\right)^{2}}{h^{2}}=1(z \geq 0) \\
\frac{4\left(y-y_{c}\right)^{2}}{w^{2}}+\frac{\left(z-z_{c}\right)^{2}}{d^{2}}=1(z<0)
\end{array}\right.
\end{gathered}
$$

Where $\left(x_{c}, y_{c}, z_{c}\right)$ is the coincident center coordinate of the upper and below semiellipsoids, $(x, y, z)$ is the coordinate on the surface of melt pool, while $w, h, d$ and $l$ are width, height, depth and length of melt pool correspondingly.

The differential equation between melt pool depth $d(t)$ with process and material parameters could be achieved as shown in Formulae (12)-(14) on the basis of melt pool shape assumption and energy conservation equation (9).

$$
\begin{gathered}
\frac{\mathrm{d} d(t)}{\mathrm{d} t}=\mathcal{F}(d(t))+\mathcal{R}(d(t)) \cdot \eta^{*} P \\
\mathcal{F}(d(t))=-\left(1+\beta_{h / d}\right)^{-1 / 2}\left(\pi \beta_{w / d}\right)^{-1 / 2}\left(\frac{3}{2} \xi \rho E_{i}\right)^{-1}\left(Q_{s c}+Q_{g c}+Q_{g r}+E_{s}\right) d(t) \\
\mathcal{R}(d(t))=\left(1+\beta_{h / d}\right)^{-3 / 2}\left(\pi \beta_{w / d}\right)^{-3 / 2}\left(\frac{3}{8} \xi \rho E_{i}\right)^{-1} d^{-1}(t)
\end{gathered}
$$

Where $\xi=\frac{4}{3}\left(\beta_{w / h} / \pi\right)^{1 / 2}\left(1+\beta_{h / d}\right)^{-1 / 2} \beta_{l / w}$. When melt pool goes into steady state, energy exchange satisfies: $\mathcal{F}(d(t))+\mathcal{R}(d(t)) \cdot \eta^{*} P=0$.

According to different melting states, the melt pool steady-state temperature is presumed as shown in Formula (15). $\lambda$ indicates the ratio of steady-state temperature 
$\left(T_{m s}\right)$ to the melting temperature $\left(T_{m}\right)$, and is adopted according to experimental observations and experience $[3,8]$.

$$
\lambda=\frac{T_{m s}}{T_{m}}=\left\{\begin{aligned}
1, & \lambda_{\text {melting }}<\mu_{I M} \\
1.2, & \mu_{I M} \leq \lambda_{\text {melting }}<\mu_{H M} \\
\frac{T_{b}+T_{m}}{2 T_{m}}, & \lambda_{\text {melting }} \geq \mu_{H M}
\end{aligned}\right.
$$

The calculation formulae of depth, width, height and length of melt pool could be derived as shown in Formulae (16)-(19) respectively:

$$
\begin{gathered}
d=\left(\frac{4 \eta^{*} P}{\left(1+\beta_{h / d}\right)\left(\pi \beta_{w / d}\right)\left(Q_{s c}+Q_{g c}+Q_{g r}+E_{s}\right)}\right)^{1 / 2} \\
w=\beta_{w / d} d \\
h=\beta_{h / d} d \\
l=\beta_{l / w} \beta_{w / d} d
\end{gathered}
$$

Where,

$$
\begin{gathered}
Q_{s c}=\xi_{s} \alpha_{s}\left(\lambda T_{m}-T_{o}\right) \\
Q_{g c}=\xi_{g} \alpha_{g}\left(\lambda T_{m}-T_{o}\right) \\
Q_{g r}=\xi_{g} \varepsilon \sigma\left(\lambda^{4} T_{m}{ }^{4}-T_{o}^{4}\right) \\
E_{s}=\rho v c_{s}\left(T_{m}-T_{o}\right) \\
\xi_{s}=2^{5 / 3} \beta_{w / h}{ }^{1 / 3} \beta_{l / w}{ }^{2 / 3}\left(1+\beta_{h / d}\right)^{-1} \\
\xi_{g}=2^{5 / 3} \beta_{w / d}{ }^{1 / 3}\left(\beta_{l / w} \beta_{h / d}\right)^{2 / 3}\left(1+\beta_{h / d}\right)^{-2}
\end{gathered}
$$

The Formulae (16)-(25) describe the mathematical link between fundamental dimensions of steady state melt pool morphology and process parameters for SLM. Where $d$ :melt pool depth, $w$ : melt pool width, $h$ : melt pool height, $l$ : melt pool length, $\eta^{*}$ :energy absorptivity of powder material, $P$ :laser power, $Q_{s c}$ : thermal conduction between melt pool and baseplate, $Q_{g c}$ : thermal convective between melt pool and the surrounding gas environment, $Q_{g r}$ : thermal radiation between melt pool and surrounding environment, $E_{s}$ : solidification specific internal energy, $\alpha_{s}$ : the equivalent convection coefficient of solid interface, $\alpha_{g}$ : convection coefficient of gas interface, $\varepsilon$ : radiation coefficient, $\sigma$ : Stefan Boltzmann constant, $\rho$ : material density, $v$ : scanning speed, $c_{s}$ : solid specific heat capacity, $\lambda$ : the ratio of steady-state temperature to the melting temperature, $T_{m}$ : material melting temperature, $T_{o}$ : material initial temperature.

$\beta_{w / d}, \beta_{h / d}$ and $\beta_{l / w}$ are the ratios of width to depth, height to depth and length to width respectively. In general, if the material and process conditions vary, the above ratio coefficients of melt pool morphology will also change. The ratio coefficients of melt pool shape are distinct in different modes and melting states. In this study, the melt pool morphologies in different melting states and modes are involved, furthermore, the ratio coefficients of melt pool morphology would be evaluated thoroughly.

\subsubsection{Estimate of melt pool ratio coefficients}

In order to calculate melt pool geometries according to Section 2.2.1, the shape 
ratio coefficients of melt pool should be evaluated, which comprise the ratios of width to depth, height to depth and length to width.

To evaluate the ratio coefficients of melt pool, temperature field theory is employed to assess the ratio coefficients of melt pool morphology. The melt pool thermal model field can be achieved from the Eagar-Tsai model [20] as shown in Formula (26).

$$
T(x, y, z, t)=\int_{-\infty}^{t} \frac{8 \eta P}{\pi C \rho\left(D^{2}+32 a(t-\delta)\right) \sqrt{\pi a(t-\delta)}} \exp \left(-\frac{8(x-v \delta)^{2}+8 y^{2}}{D^{2}+32 a(t-\tau)}-\frac{z^{2}}{4 a(t-\delta)}\right) \mathrm{d} \delta
$$

Where $x, y, z$ and $t$ denote $\mathrm{x}$-axis, $\mathrm{y}$-axis, $\mathrm{z}$-axis coordinate position in Cartesian coordinate system and time respectively; and $\delta$ denotes the differential variable of time.

Considering that melt pool reaches the steady state, the integrated dimensionless variables of process parameters are introduced as $\tau=a / v D$ and $\zeta=\eta P / \pi H_{s l} \sqrt{\pi a v D^{3}}$. Likewise, variables $x^{\prime}=4 x / D, y^{\prime}=4 y / D, z^{\prime}=4 z / D$, and $\delta^{\prime}=4(x-v \delta) / D$ are adhibited, then the temperature field can be expressed as Formula (27).

$$
T(x, y, z, 0)=\zeta \int_{0}^{\infty} \frac{1}{\left(2+\tau \delta^{\prime}\right) \sqrt{\delta^{\prime}}} \exp \left(-\frac{\left(x^{\prime}-\delta^{\prime}\right)^{2}+y^{\prime 2}}{2+\tau \delta^{\prime}}-\frac{z^{\prime 2}}{\tau \delta^{\prime}}\right) \mathrm{d} \delta^{\prime}
$$

The ratios of width to depth and length to width of melt pool can be estimated by Formula (28):

$$
\beta_{w / d}=\frac{\max \left|m_{y}-n_{y}\right|}{\max \left|m_{z}-n_{z}\right|}, \beta_{l / w}=\frac{\max \left|m_{x}-n_{x}\right|}{\max \left|m_{y}-n_{y}\right|} \forall m \in U, n \in U, U=\left\{p \mid T^{p}=T_{m}\right\}
$$

Where $p$ denotes the point in the baseplate, $T^{p}$ denotes the temperature at the point of $p, U$ indicates the set of points whose temperature value equals melting temperature, and $m$ and $n$ represent any two points in $U$.

To estimate melt pool ratio of height to depth, the upper portion of melt pool above the build surface is analyzed as shown in Formula (29) based on mass conservation, where the thickness of powder layer is assumed to be uniform and even, and the impacts of random spatter and denudation of the powder are ignored.

$$
\rho_{s} \frac{\pi}{4} l w h \approx \rho_{p} l w L_{t}
$$

The left side of Equation (29) represents the mass of solidified melt pool above the build surface, while the right side indicates the mass of the powder. $l, w$ and $h$ denote the maximum length, width and height of the upper melt pool, $\rho_{s}$ and $\rho_{p}$ denote the solid and powder material density respectively.

In this research, we adopted the manner of extracting and fitting through physical mechanism to estimate the shape ratios of melt pool. According to melt pool melting states, the expressions of the ratio coefficients are displayed as Equation (30):

$$
\boldsymbol{\beta}= \begin{cases}\boldsymbol{\beta}^{\boldsymbol{L}}=\left[\beta_{w / d}^{L}, \beta_{h / d}^{L}, \beta_{l / w}^{L}\right], & \lambda_{\text {melting }}<\mu_{I M} \\ \boldsymbol{\beta}^{I}=\left[\beta_{w / d}^{I}, \beta_{h / d}^{I}, \beta_{l / w}^{I}\right], & \mu_{I M} \leq \lambda_{\text {melting }}<\mu_{H M} \\ \boldsymbol{\beta}^{\boldsymbol{H}}=\left[\beta_{w / d}^{H}, \beta_{h / d}^{H}, \beta_{l / w}^{H}\right], & \lambda_{\text {melting }} \geq \mu_{H M}\end{cases}
$$

Where $\beta_{w / d}^{i}, \beta_{h / d}^{i}$ and $\beta_{l / w}^{i}$ denote the ratios of width to depth, height to depth 
and length to width, while the superscript $i(H, I$, or $L)$ denotes high melting, intermediate melting and low melting respectively.

The specific mathematical expressions for computing the ratio coefficients under different melting states are introduced and elaborated in the following.

1) High melting (HM) state

From the Formula (27), it can be concluded that the steady-state temperature field is the function of $\tau$ and $\zeta$, where $\tau=a / v D$ and $\zeta=\Delta H /\left(H_{\mathrm{sl}} \sqrt{\pi}\right)$. Where, $a$ : thermal diffusivity, $v$ : scanning speed, $D$ : laser beam diameter, and $\Delta H / H_{\mathrm{sl}}$ : normalized enthalpy.

When $\lambda_{\text {melting }} \geq \mu_{H M}$, namely, $\zeta \geq \mu_{H M} C_{\text {lackfusion }} / \sqrt{\pi}$, melt pool is in HM state. According to Formulae (27)-(29), ratio coefficients $\boldsymbol{\beta}^{H}=\left\{\beta_{w / d}^{H}, \beta_{h / d}^{H}, \beta_{l / w}^{H}\right\}$ under HM state are calculated and fitted as Formulae (31)-(33).

$$
\begin{gathered}
\beta_{w / d}^{H}=\frac{0.012+0.42 \tau+1.3 \tau^{2}+(1.41+1.01 \zeta) \tau^{2} \ln \tau+\zeta\left(-0.0080+0.19 \tau+1.76 \tau^{2}\right)}{\zeta \tau^{\frac{5}{2}}} \\
\beta_{h / d}^{H}=\frac{4 \sqrt{\tau} \rho_{p} L_{t}}{\pi \rho_{s} D[0.0028 \zeta+0.040 \tau+0.10 \zeta \tau-(0.30+0.019 \zeta) \tau \ln \tau+\ln \zeta(0.89 \tau-0.28 \tau \ln \tau)]} \\
\beta_{l / w}^{H}=\frac{\zeta \tau}{0.36-2.79 \tau+3.67 \tau^{2}-(4.04+0.16 \zeta) \tau^{2} \ln \tau+\zeta\left(-0.0058+0.035 \tau+0.44 \tau^{2}\right)}
\end{gathered}
$$

Where $\rho_{p}, \rho_{s}, D, L_{t}$ denote the powder density, solid density, laser beam diameter and layer thickness respectively.

2) Low melting (LM) state

When $\lambda_{\text {melting }}<\mu_{I M}$, namely, $\zeta<\mu_{I M} C_{\text {lackfusion }} / \sqrt{\pi}$, melt pool is in LM state. melt pool in low melting state is generally in conduction mode. The empirical model under conduction mode can be achieved from [25], which is suitable for estimating some melt pool shape ratios in LM state. Combined with Formula (28)-(29), the estimation of $\boldsymbol{\beta}^{L}=\left\{\beta_{w / d}^{L}, \beta_{h / d}^{L}, \beta_{l / w}^{L}\right\}$ of melt pool in LM state could be concluded and fitted as Formulae (34)-(36) respectively.

$$
\begin{gathered}
\beta_{w / d}^{L}=\pi k T_{b}\left(\sqrt{\varphi^{2}+4 \eta P \phi}-\varphi\right)\left[\eta P \phi \ln \left(\frac{D+a / v}{D}\right)\right]^{-1} \\
\beta_{h / d}^{L}=8 k T_{b} \rho_{p} L_{t}\left[\rho_{s} \eta P \ln \left(\frac{D+a / v}{D}\right)\right]^{-1} \\
\beta_{l / w}^{L}=\frac{2 D \phi\left[0.0049-0.21 \tau+1.3 \tau^{2}+(-0.11-0.17 \zeta) \tau^{2} \ln \tau++\zeta\left(-0.0062+0.23 \tau+0.75 \tau^{2}\right)\right]}{\tau^{2}\left(\sqrt{\varphi^{2}+4 \eta P \phi}-\varphi\right)}
\end{gathered}
$$

Where $\phi=\pi \exp (1) \rho \operatorname{Cv}\left(T_{m}-T_{o}\right), \varphi=\pi k\left(T_{m}-T_{o}\right), \rho$ : material density, $C$ : specific heat, $v$ : scanning speed, $k$ : thermal conductivity, $T_{m}$ : melting temperature, $T_{o}$ : initial temperature, $T_{b}$ : boiling temperature, $a$ : thermal diffusivity, $\eta:$ laser absorptivity of solid material, $P$ : laser beam power, $D$ : laser beam diameter.

3 ) Intermediate melting (IM) state

When $\mu_{I M} \leq \lambda_{\text {melting }}<\mu_{H M}$, namely, $\mu_{I M} C_{\text {lackfusion }} / \sqrt{\pi} \leq \zeta<\mu_{H M} C_{\text {lackfusion }} /$ $\sqrt{\pi}$, melt pool is in IM state. According to Formulae (27)-(29), ratio coefficients $\boldsymbol{\beta}^{\boldsymbol{I}}=$ $\left\{\beta_{w / d}^{I}, \beta_{h / d}^{I}, \beta_{l / w}^{I}\right\}$ under IM state could be obtained and fitted as Formulae (37)-(39). 


$$
\begin{gathered}
\beta_{w / d}^{I}=\frac{\sqrt{\tau}\left(\sqrt{\varphi^{2}+4 \phi P \eta}-\varphi\right)}{2 \phi D[0.0028 \zeta+0.040 \tau+0.10 \zeta \tau-(0.30+0.019 \zeta) \tau \ln \tau+\ln \zeta(0.89 \tau-0.28 \tau \ln \tau)]} \\
\beta_{h / d}^{I}=\frac{4 \sqrt{\tau} \rho_{p} L_{t}}{\pi \rho_{s} D[0.0028 \zeta+0.040 \tau+0.10 \zeta \tau-(0.30+0.019 \zeta) \tau \ln \tau+\ln \zeta(0.89 \tau-0.28 \tau \ln \tau)]} \\
\beta_{l / w}^{I}=\frac{\zeta \tau}{0.36-2.79 \tau+3.67 \tau^{2}-(4.04+0.16 \zeta) \tau^{2} \ln \tau+\zeta\left(-0.0058+0.035 \tau+0.44 \tau^{2}\right)}
\end{gathered}
$$

Where $\phi=\pi \exp (1) \rho C v\left(T_{m}-T_{o}\right), \varphi=\pi k\left(T_{m}-T_{o}\right), \eta$ : laser absorptivity of solid material, $P$ : laser beam power, $\rho_{p}$ : powder density, $\rho_{s}$ : solid density, $D$ : laser beam diameter, $L_{t}$ : layer thickness.

Taken together, the above formulae based on the mechanism of temperature field and mass conservation could be employed to estimate the ratio coefficients of melt pool morphologies for distinct melting states.

According to the melting degree index in Section 2.1, the melting state of melt pool could be assessed. Then, with Formulae (31)-(39), the shape ratio coefficients of melt pool, covering width to depth, height to depth and length to width, can be estimated. Afterwards, the essential geometries of melt pool are available to be calculated through Formulae (16)-(25). The following section elaborates the realization process of the proposed approach for calculating critical melt pool geometries.

\subsection{Calculation procedure}

The calculation flow of melt pool morphology is shown in Fig.6. According to the defined process parameter index, a preliminary qualitative analysis of melt pool status could be conducted. Then the ratio coefficients of melt pool shape are estimated based on the mechanisms of melt pool temperature field and mass conversion. Thereafter the critical geometries of melt pool could be calculated, containing the width, height, depth and length based on energy transfer principle. Lastly, the melt pool morphology status can be evaluated. Furthermore, melt pool classification and melt pool morphology prediction are realized. And the proposed calculation approach is implemented in Matlab. 


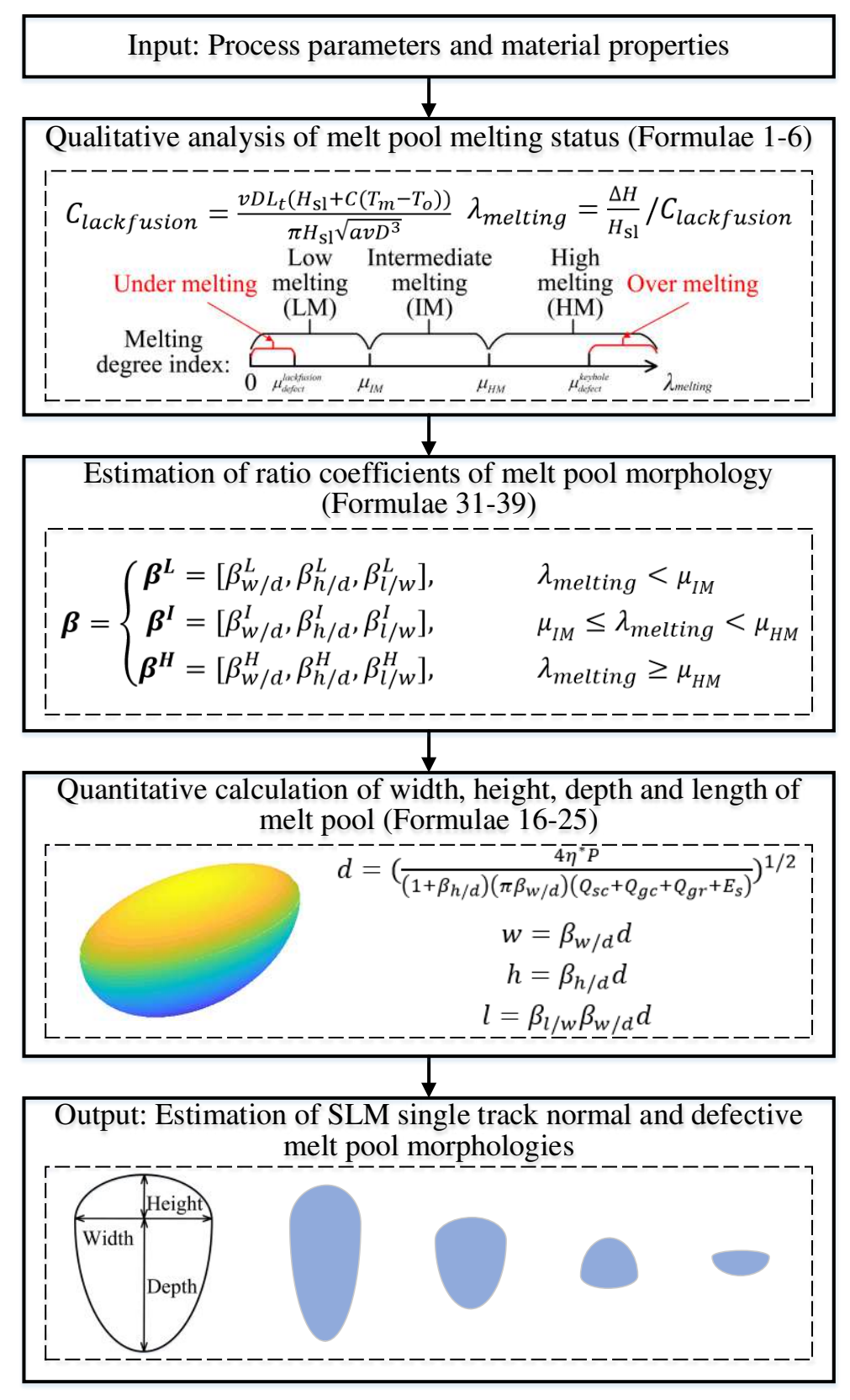

Fig.6 Flowchart of melt pool morphology calculation approach

The specific calculation steps of the proposed method are elaborated as follows:

1) Qualitative analysis of melt pool melting status

Preliminarily assessing of melt pool melting status could be conducted according to the defined process parameter index. From Section 2.1, it can be acknowledged that parameters $\mu_{I M}, \mu_{H M}$ are adopted to classify melt pool melting states. The under melting critical coefficient $\mu_{\text {defect }}^{\text {lackfun }}$ and over melting critical coefficient $\mu_{\text {defect }}^{\text {keyhole }}$ are utilized to distinguish whether under melting or over melting defects of melt pool might occur. The specific values of above thresholds can be adopted according to Table 1.

The melting states of melt pool and possibly normal or defective morphologies are preliminarily estimated by the defined melting degree index $\lambda_{\text {melting }}$. The criteria are as follows: 
i) If $\lambda_{\text {melting }} \geq \mu_{H M}$, melt pool would lie in HM state. In HM state, especially when $\lambda_{\text {melting }} \geq \mu_{\text {defect }}^{\text {keyhole }}$, over melting defects are prone to appear, such as serious keyhole and keyhole porosity defect, etc.

ii) If $\mu_{I M} \leq \lambda_{\text {melting }}<\mu_{H M}$, melt pool would lie in IM state. It is likely to produce regular melt pool morphologies in IM state, but some inapparent defects may also occur.

iii ) If $\lambda_{\text {melting }}<\mu_{I M}$, melt pool would be in LM state. In LM state, particularly when $\lambda_{\text {melting }} \leq \mu_{\text {defect }}^{\text {lackfunion }}$, under melting defects may appear probably, such as lack of fusion and balling fault, etc.

2) Estimation of ratio coefficients of melt pool morphology

Ratio coefficients of melt pool morphology could be estimated according to the melting degree of melt pool from Section 2.2.2. The calculation criteria of ratio coefficients of melt pool structure are suggested as follows:

i) In HM state, the formulae of $\boldsymbol{\beta}^{\boldsymbol{H}}$ are normally preferred.

ii) The formulae of $\boldsymbol{\beta}^{\boldsymbol{I}}$ is favored in IM state.

iii ) The formulae of $\boldsymbol{\beta}^{\boldsymbol{L}}$ is suggested in LM state.

3) Quantitative calculation of melt pool geometries

According to the computational Formulae (16)-(25), the width, height, depth and length of melt pool could be calculated, and the normal and abnormal melt pool morphologies would be predicted through process parameters and material properties accordingly. Additionally, its application in melt pool classification, melt pool morphology reconsitution and prediction could be implemented.

\section{Comparison study of the model}

The experimental instances of SLM melt pools in published literature were employed to verify the proposed model. The geometries of melt pool of three frequently-used materials involving Inconel 718 (IN718), Ti6A14V (TC4) and SS316L (316L) have been calculated and compared. Meanwhile the processing conditions adopted are consistent with those in the corresponding cited literature.

\subsection{Comparison with experimental observations}

The geometrical dimensions of melt pool were computed according to the calculation procedure from Section 2.3 for distinct materials, and the calculation outcomes were compared with the experimental data sets from the literature correspondingly for SLM process. Table 2 represents the error results of melt pool morphologies between calculation and experiment for IN718, TC4 and 316L materials. And sufficient groups of melt pool samples from literature were utilized and contrasted. Results indicate that the calculated melt pool dimensions are in good agreement with the experimental data for distinct materials, machines and process conditions. The adopted material parameters of IN718, TC4 and 316L for calculation are shown in Table 3 in Appendix A.

The average errors of width, depth, height and length of melt pool are $12.66 \%$, $22.59 \%, 21.64 \%$ and $22.25 \%$ respectively, which prove that the proposed model can 
effectively calculate the sizes of melt pool shape. The prediction accuracy of melt pool width is relatively higher due to the minor fluctuation and instability in the width dimension. Melt pool depth is affected by the evaporation phenomenon and recoiling force, and the fluctuation is more intensive, leading to lower prediction accuracy, which is consistent with the conclusion of reference [11]. Meanwhile, height of melt pool is affected by surface tension and balling phenomenon. Thus the uncertainty is relatively larger as well. Also, melt pool length is greatly influenced by melt pool modes [16], the fluctuation of which is also large.

According to the identification criteria of keyhole mode from $[15,26]$, keyhole mode and conduction mode are classified in Table 2. Results depict that the proposed technique is available for both conduction and keyhole mode. As the stability of melt pool in keyhole mode is relatively poorer, the phenomena of evaporation and splashing are likely to occur. The uncertainty of keyhole mode is higher than conduction mode. Accordingly, the overall calculation accuracy for keyhole mode is lower than that of conduction mode.

Table 2 Errors of melt pool dimensions between calculation and experimental data sets from literature for distinct materials, machines and process conditions

\begin{tabular}{|c|c|c|c|c|c|c|c|c|c|c|}
\hline \multirow{2}{*}{ Material } & \multirow{2}{*}{ Ref } & \multirow{2}{*}{ Machine $^{\mathrm{a}}$} & \multirow{2}{*}{$\begin{array}{c}\text { Process } \\
\text { conditions }^{\mathrm{b}}\end{array}$} & \multirow{2}{*}{$\begin{array}{l}\text { Melt pool } \\
\text { dimension }\end{array}$} & \multicolumn{2}{|c|}{$\begin{array}{c}\text { Full } \\
\text { sample }\end{array}$} & \multicolumn{2}{|c|}{$\begin{array}{l}\text { Conduction } \\
\text { sample }\end{array}$} & \multicolumn{2}{|c|}{$\begin{array}{l}\text { Keyhole } \\
\text { sample }\end{array}$} \\
\hline & & & & & $\mathrm{N}^{\mathrm{c}}$ & $\begin{array}{l}\text { Error } \\
(\%)\end{array}$ & $\mathrm{N}$ & $\begin{array}{l}\text { Error } \\
(\%)\end{array}$ & $\mathrm{N}$ & $\begin{array}{c}\text { Error } \\
(\%)\end{array}$ \\
\hline \multirow{4}{*}{ IN718 } & [27] & $\begin{array}{c}\text { EOS } \\
\text { M280 }\end{array}$ & $\begin{array}{c}P: 100-300 \\
v: 0.2-2.5 ; L_{t}: 40 \\
\mathrm{D}: 100\end{array}$ & $\begin{array}{l}\text { width } \\
\text { depth }\end{array}$ & 12 & $\begin{array}{l}10.97 \\
26.53\end{array}$ & 5 & $\begin{array}{c}7.66 \\
44.33\end{array}$ & 7 & $\begin{array}{l}13.34 \\
13.81\end{array}$ \\
\hline & {$[11]$} & $\begin{array}{l}\text { EOS } \\
\text { M290 }\end{array}$ & $\begin{array}{c}P: 100-339 \\
v: 0.2-1.2 ; L_{t}: 40 \\
\mathrm{D}: 100\end{array}$ & $\begin{array}{l}\text { width } \\
\text { depth }\end{array}$ & 28 & $\begin{array}{l}10.48 \\
15.00\end{array}$ & 13 & $\begin{array}{l}11.16 \\
14.24\end{array}$ & 15 & $\begin{array}{c}9.88 \\
15.65\end{array}$ \\
\hline & [28] & $\begin{array}{l}\text { Concept } \\
\text { M1 }\end{array}$ & $\begin{array}{c}P: 180 ; v: 0.4- \\
0.8 ; L_{t}: 40 \\
\text { D: } 100\end{array}$ & $\begin{array}{l}\text { width } \\
\text { length }\end{array}$ & 3 & $\begin{array}{l}17.68 \\
24.13\end{array}$ & 1 & $\begin{array}{l}18.22 \\
18.85\end{array}$ & 2 & $\begin{array}{l}19.78 \\
19.02\end{array}$ \\
\hline & [29] & $\begin{array}{l}\text { Tongtai } \\
\text { AM250 }\end{array}$ & $\begin{array}{c}P: 180 ; v: 0.4- \\
0.8 ; L_{t}: 40 ; \mathrm{D}: 54\end{array}$ & $\begin{array}{l}\text { width } \\
\text { length }\end{array}$ & 3 & $\begin{array}{c}8.96 \\
20.38\end{array}$ & 0 & & 3 & $\begin{array}{c}8.96 \\
20.38\end{array}$ \\
\hline \multirow[t]{2}{*}{ TC4 } & {$[30]$} & Custom & $\begin{array}{l}P: 100-500 \\
v: 0.1-1 ; L_{t}: 20- \\
\text { 60; D:100 }\end{array}$ & $\begin{array}{l}\text { width } \\
\text { depth } \\
\text { height }\end{array}$ & 19 & $\begin{array}{l}16.07 \\
19.54 \\
21.14\end{array}$ & 7 & $\begin{array}{l}19.18 \\
28.10 \\
13.95\end{array}$ & 12 & $\begin{array}{l}14.26 \\
14.55 \\
25.34\end{array}$ \\
\hline & [31] & $\begin{array}{c}\text { IPG } \\
\text { Photonics }\end{array}$ & $\begin{array}{l}P: 20-50 ; v: 0.1- \\
0.3 ; L_{t}: 0 ; \mathrm{D}: 70\end{array}$ & $\begin{array}{l}\text { width } \\
\text { depth }\end{array}$ & 9 & $\begin{array}{c}9.51 \\
10.72\end{array}$ & 9 & $\begin{array}{c}9.51 \\
10.72\end{array}$ & 0 & \\
\hline & [15] & Custom & $\begin{array}{l}P: 100-500 \\
v: 0.15-1.5 ; \\
L_{t}: 75 ; \mathrm{D}: 55\end{array}$ & $\begin{array}{l}\text { width } \\
\text { depth } \\
\text { height }\end{array}$ & 26 & $\begin{array}{l}14.32 \\
36.55 \\
17.50\end{array}$ & 7 & $\begin{array}{c}11.89 \\
9.75 \\
20.32\end{array}$ & 19 & $\begin{array}{l}15.21 \\
46.43 \\
16.46\end{array}$ \\
\hline $316 \mathrm{~L}$ & [32] & $\begin{array}{c}\text { Concept } \\
\text { M2 }\end{array}$ & $\begin{array}{c}P: 150-400 \\
v: 0.5-1.8 ; L_{t}: 30 \\
\mathrm{D}: 54\end{array}$ & $\begin{array}{l}\text { width } \\
\text { depth } \\
\text { height }\end{array}$ & 14 & $\begin{array}{l}15.03 \\
20.21 \\
29.98\end{array}$ & 8 & $\begin{array}{l}11.94 \\
10.97 \\
23.51\end{array}$ & 6 & $\begin{array}{l}19.14 \\
32.53 \\
38.66\end{array}$ \\
\hline & [33] & Phenix & $\begin{array}{c}P: 50 ; v: 0.12- \\
0.24 ; L_{t}: 50 \\
\text { D: } 100\end{array}$ & width & 4 & 3.91 & 4 & 3.91 & 0 & \\
\hline
\end{tabular}


a 'Custom' denotes self-developed;

b ' $P$ ' denotes laser beam power $(\mathrm{W})$, ' $v$ ' denotes scanning speed $(\mathrm{m} / \mathrm{s}),{ }^{\prime} L_{t}$ ' denotes layer thickness $(\mu \mathrm{m})$, ' $D$ ' denotes laser beam diameter $(\mu \mathrm{m})$;

$\mathrm{c}$ ' $\mathrm{N}$ ' denotes the amount of sample group.

Energy absorptivity is an important material parameter in the proposed method, which is affected by material, laser wavelength [19], powder particle morphology [34], melting state [35], morphology of melt pool [3, 35] and laser beam diameter [14], etc.

In this research, energy absorptivity of powder material is taken in the range of 0.2 $\sim 0.95$, and the values of pure solid absorptivity range from 0.1 to 0.3 . And the adopted specific energy absorptivity values are shown in Table 4-6 in Appendix B. Distinct discrete values are adopted for different melting states and modes of melt pool. The HM and keyhole mode generally take larger powder energy absorptivity, such as $0.7 \sim 0.95$. Powder energy absorptivity domain of $0.4 \sim 0.8$ is typically adopted in IM state. While in LM state, powder energy absorptivity is employed among 0.2 and 0.5 . The scope of energy absorptivity adopted in this study is consistent with that in [14], [19] and [36]. The material absorptivity researched in reference [14] ranges from 0.23 to 0.89 . And the absorptivity of IN718 investigated in reference [19] lies between 0.3 and 0.87 in SLM process. The range of absorptivity measured from reference [36] is as follows: If laser wavelength is $10.6 \mu \mathrm{m}$, absorptivity ranges from 0.23 to 0.96 . If the wavelength is $1.06 \mu \mathrm{m}$, absorptivity ranges from 0.02 to 0.82 .

The energy absorptivity of powder material is higher than that of pure solid material $[29,36]$. Typically, energy absorptivity holds a positive correlation with the melting degree [18]. And energy absorptivity in keyhole mode is larger than that in conduction mode $[11,35]$. If melt pool shape varies, laser reflection and refraction would also change, resulting in distinct laser energy absorptivity. Energy absorptivity of material is arduous to determine. As a consequence, it is indispensable to estimate the absorptivity according to experience under actual situations. In this paper, energy absorptivity is discretely valued according to the melting degree and working mode of melt pool. Energy absorptivity could be selected optimally to achieve higher calculation accuracy of the proposed model.

\subsection{Comparison with existing models}

The computational model proposed in this study is also contrasted with the existing analogous models. As the remaining models cannot compute all the melt pool geometrical dimensions. Specifically, the formulae from Rubenchik et al. [16] can calculate the width and depth of melt pool, while equations from Tang et al. [18] and Gladush-Smurov model [25] could compute the width or depth of melt pool alone correspondingly. Thus this section mainly compares the melt pool width and depth that the above existing models are available to calculate.

The contrastive outcomes of melt pool width calculated by the proposed model, Rubenchik et al. [16] and Tang et al. [18] under the processing conditions of references [15], [30] and [32] are shown in Fig.7 (a), (b) and (c) respectively. Results imply that 
the accuracy of the proposed model is better relative to the Rubenchik et al. model and Tang et al. model under the material and process conditions of cited references. Meanwhile, computational error of the proposed model is normally controlled within $20 \%$.

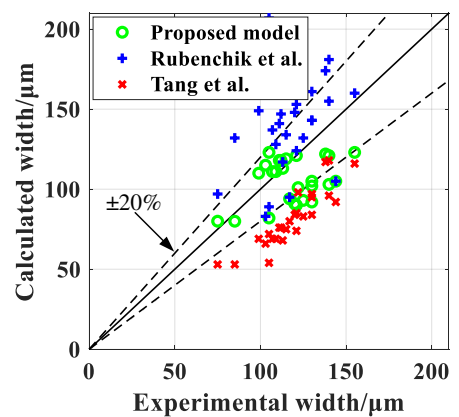

(a)

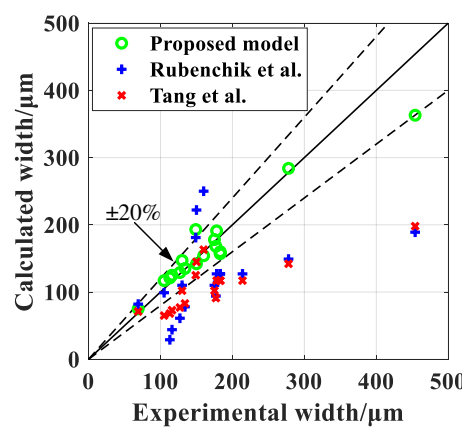

(b)

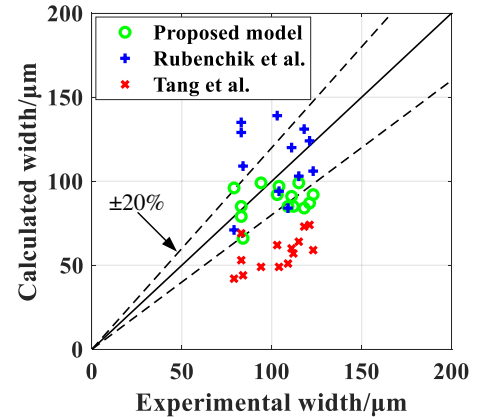

(c)

Fig.7 Comparison of melt pool width calculated by distinct existing models under reference conditions (a) Reference [15] (b) Reference [30] (c) Reference [32]

The calculation results of melt pool depth through the proposed model, Rubenchik et al. [16] and Gladush-Smurov model [25] under the material and process conditions of references [11], [27] and [32] are shown in Fig.8 (a), (b) and (c) correspondingly. Results infer that the accuracy of the proposed model is higher than that of Rubenchik et al. and Gladush-Smurov under the conditions of quoted references. For the reason that Rubenchik et al. model and Gladush-Smurov model were derived relying on the thermal field mechanism alone, where no more material and energy transfer principles of melt pool are involved adequately, their calculation accuracy are more flawed than the proposed model. And the error of the proposed model is mainly controlled within $30 \%$.

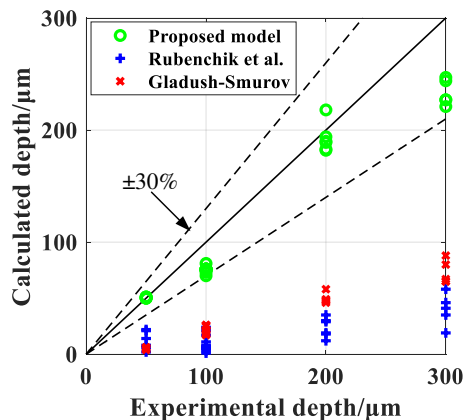

(a)

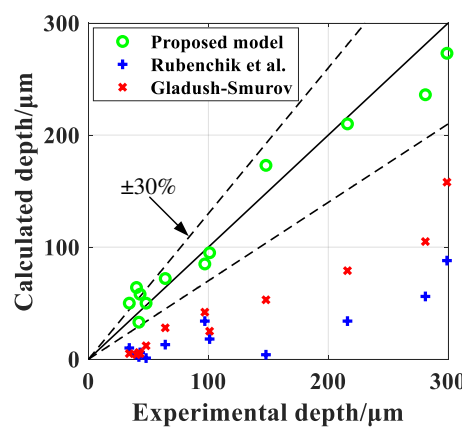

(b)

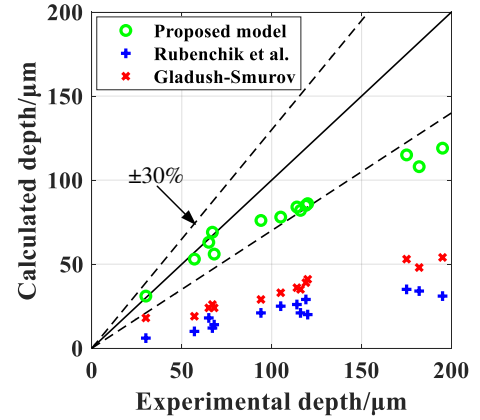

(c)

Fig.8 Comparison of melt pool depth calculated by distinct existing models under reference conditions (a) Reference [11] (b) Reference [27] (c) Reference [32]

\subsection{The application of the model in melt pool classification}

The proposed model was conducted to estimate the melt pool morphology types under the process conditions from reference [12], and four kinds of representative melt pool morphologies were obtained under diverse combinations of laser beam power and scanning speed, the outcomes of which are shown in Fig.9. Four types of melt pool 
morphologies consist of severe keyhole, under melting, balling and desirable nominated according to reference [12]. Four types of melt pool morphologies are evaluated based on the following criteria: a) When the ratio of depth to width satisfies the inequality equation, that is $1 / \beta_{w / d} \geq 1.25$, melt pool belongs to severe keyhole. b) If melt pool depth does not exceed the layer thickness, i.e. $d \leq L_{t}$, melt pool attributes to under melting. c) When the ratio of height to layer thickness satisfies the inequality relation, that is $h / L_{t} \geq 1.5$, the melt pool type pertains to balling. d) Otherwise, the melt pool type is classified as desirable. Results manifest that the proposed model enables the effective identification of melt pool types through process parameters, which is consistent with the experimental outcomes from the corresponding reference. It is noteworthy that the balling type in Fig.9 (a) whose percentage is less than 50\% is not belong to balling type in our opinion and we make black box mark around the percentage.

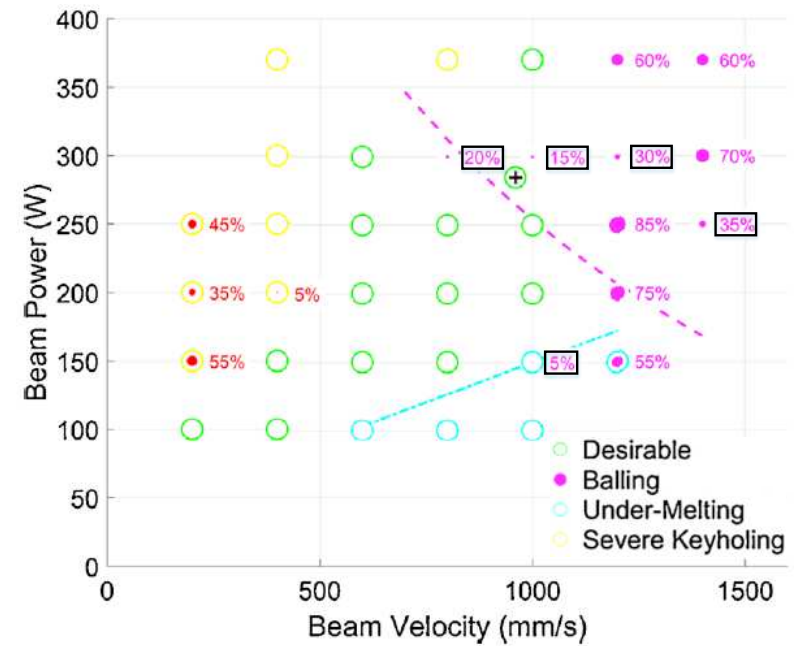

(a)

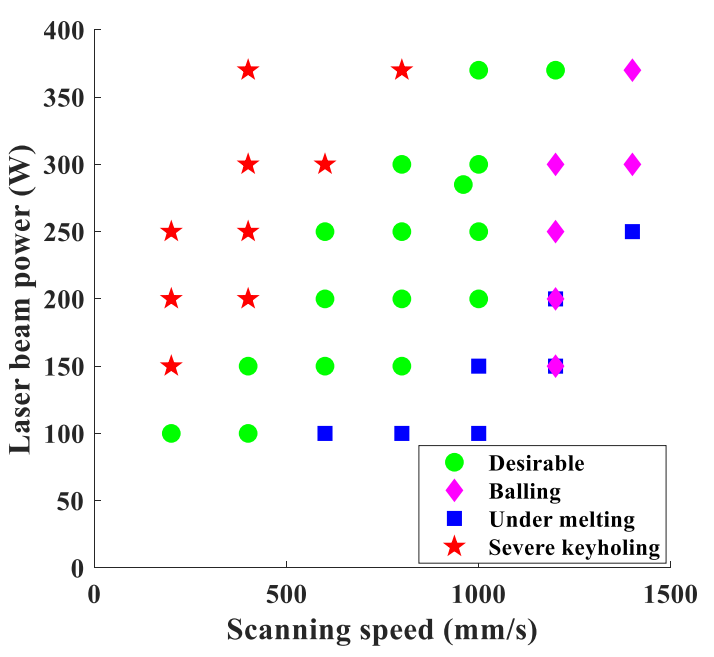

(b)

Fig.9 Mapping between process parameters and melt pool morphology types (a) Experimental results from reference [12] (b) Results from proposed model

\subsection{The application of the model in melt pool morphology prediction}

The cross-section morphologies of melt pools under distinct material and process parameter conditions were analyzed in this section. The quintessential contrasted results of melt pool cross-section morphologies between calculation and experiment of IN718 material under process conditions from [11] are shown in Fig.10. Fig.10 (a) exhibits the severe keyhole defective melt pool morphology in keyhole mode. Fig.10 (b) depicts the normal morphology in keyhole mode. The outcomes are consistent with the actual cross section morphologies of melt pool and suggest that the proposed model could effectively predict the normal and defective melt pool morphologies for IN718 under the condition of reference [11].

It could be concluded that normal or defective melt pool morphology may be triggered in keyhole mode. As shown in Fig.10 (a) the serious keyhole melt pool

occurred when $\lambda_{\text {melting }}=8.2\left(\lambda_{\text {melting }}>\mu_{\text {defect }}^{\text {keyhole }}=7.0\right)$. If the value of $\lambda_{\text {melting }}$ is 
moderate, relatively regular melt pool morphology is likely to arise. As depicted in Fig.10 (b), the normal melt pool occurred when $\lambda_{\text {melting }}=3.9 \quad\left(1.8=\mu_{\text {defect }}^{\text {lackfun }}<\right.$ $\lambda_{\text {melting }}<\mu_{\text {defect }}^{\text {keyhole }}=7.0$ ).

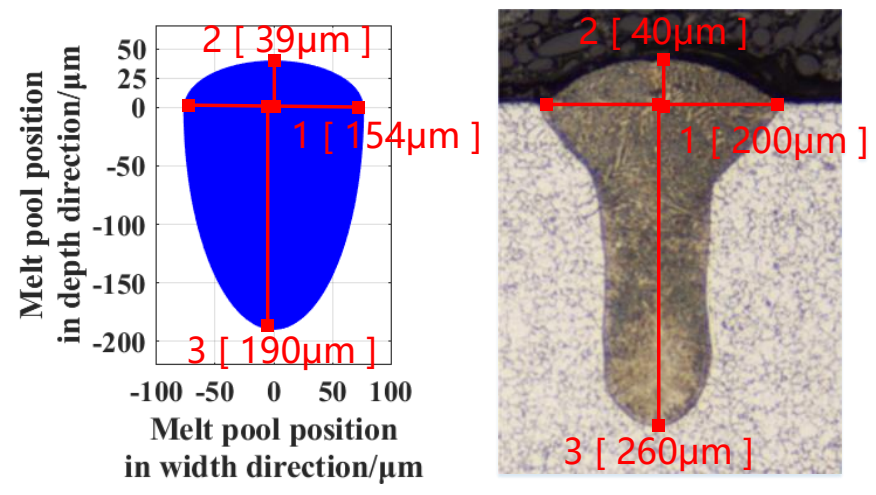

Laser power : 250W; Scanning speed : $0.4 \mathrm{~m} / \mathrm{s}$; Layer thickness : $40 \mu \mathrm{m}$; Beam diameter : $100 \mu \mathrm{m}$

(a)

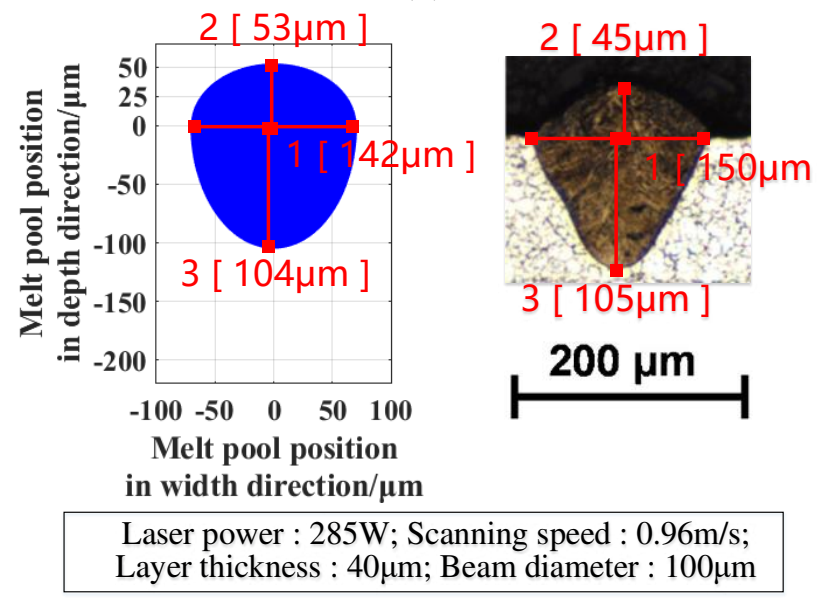

(b)

Fig.10 Comparison of calculated and experimental cross-section morphologies (adapted from

[11]) of IN718 (a) Severe keyhole defect (b) Normal morphology (All graphs are presented at the same size scale)

The comparison diagram of melt pool cross section morphologies between calculation and experiment of TC4 material from reference [30] is shown in Fig.11. Specifically, Fig.11 (a)-(c) show the severe keyhole defect, normal and balling melt pool morphologies respectively. As shown in Fig. 11 (a), severe keyhole melt pool defect occurred when $\lambda_{\text {melting }}=16.1\left(\lambda_{\text {melting }}>\mu_{\text {defect }}^{\text {keyhole }}=12.7\right)$. If the value of $\lambda_{\text {melting }}$ is appropriate, it is likely to appear relatively regular melt pool shape. As indicated in Fig.11 (b), the normal melt pool generated when $\lambda_{\text {melting }}=6.4 \quad\left(3.9=\mu_{\text {defect }}^{\text {lackfun }}<\right.$ $\left.\lambda_{\text {melting }}<\mu_{\text {defect }}^{\text {keyhole }}=12.7\right)$. If $\lambda_{\text {melting }}$ scores too small, under melting phenomenon would emerge. As shown in Fig.11 (c), the balling melt pool defect (lack of fusion) exhibited when $\lambda_{\text {melting }}=3.2\left(\lambda_{\text {melting }}<\mu_{\text {defect }}^{\text {lackfun }}=3.9\right)$. The results are consistent with the actual melt pool cross section morphologies and demonstrate that the proposed calculation model could effectively evaluate the normal and defective melt pool morphologies for TC4 from reference [30]. 

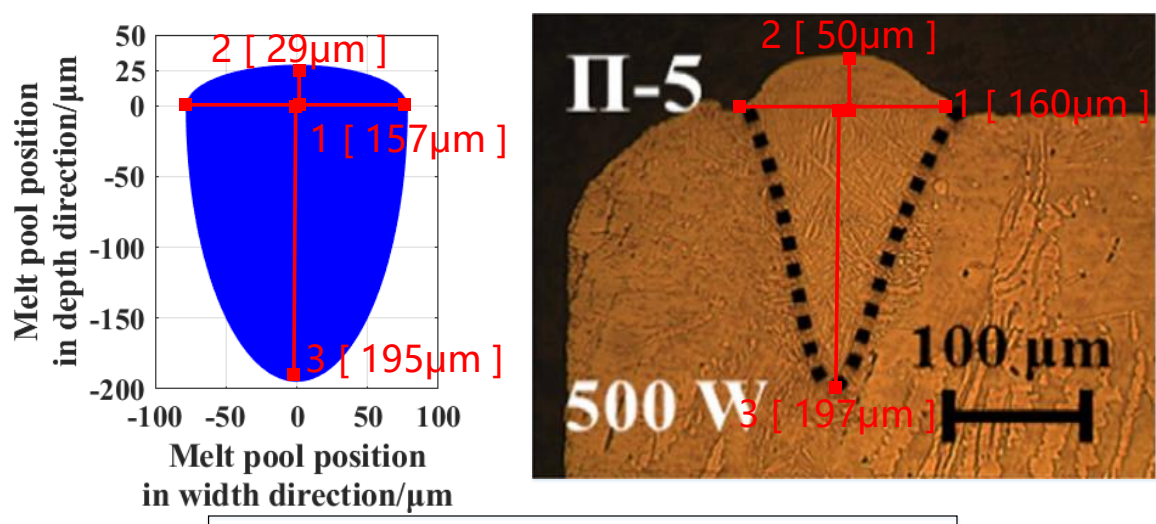

in width direction/ $\mu \mathrm{m}$

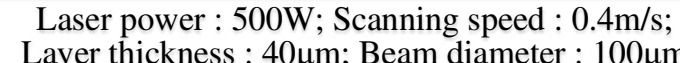

(a)
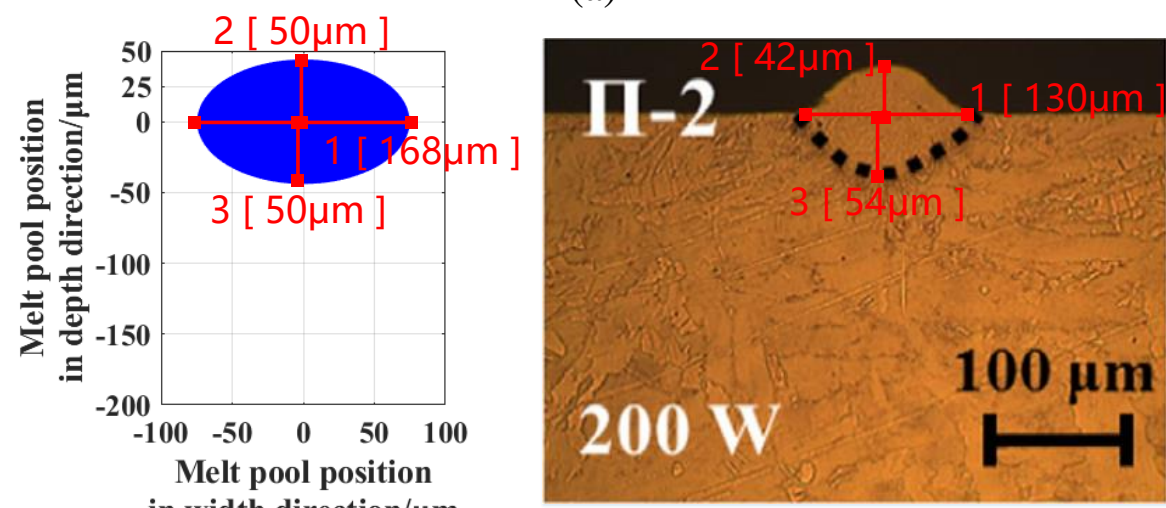

in width direction $/ \mu \mathrm{m}$

Laser power : 200W; Scanning speed : $0.4 \mathrm{~m} / \mathrm{s}$; Layer thickness : $40 \mu \mathrm{m}$; Beam diameter : $100 \mu \mathrm{m}$

(b)

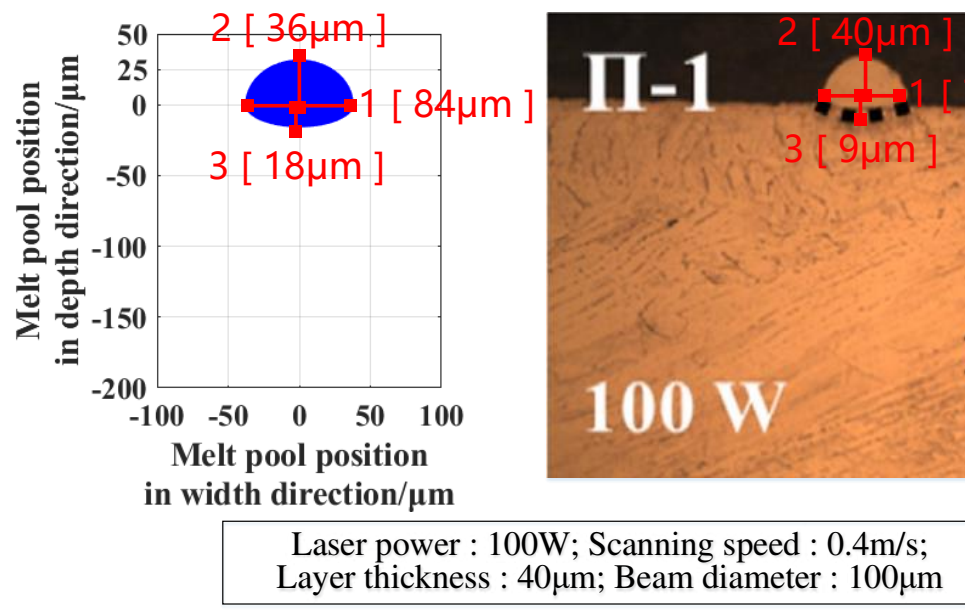

(c)

Fig.11 Comparison of calculated and experimental cross-section morphologies (adapted from [30]) of TC4 (a) Severe keyhole defect (b) Normal morphology (c) Balling defect (All graphs are presented at the same size scale)

As shown in Fig.12, the experimental melt pool cross section morphologies from reference [32] of 316L material were compared with the calculation. Fig.12 (a) and (b) display the normal and slightly balling melt pool shape respectively. As shown in Fig.12 (a) the normal melt pool occurred when $\lambda_{\text {melting }}=4.3 \quad\left(1.3=\mu_{\text {defect }}^{\text {lack }}<\lambda_{\text {melting }}<\right.$ 
$\left.\mu_{\text {defect }}^{\text {keyhole }}=5.7\right)$. As shown in Fig.12 (b), melt pool of slightly balling emerged when $\lambda_{\text {melting }}=3.6\left(1.3=\mu_{\text {defect }}^{\text {lackfus }}<\lambda_{\text {melting }}<\mu_{\text {defect }}^{\text {keyhole }}=5.7\right)$. The outcomes coincide with the realistic cross section morphologies of melt pool and prove that the proposed model could effectively forecast the normal and defective melt pool morphologies for $316 \mathrm{~L}$ from reference [32].

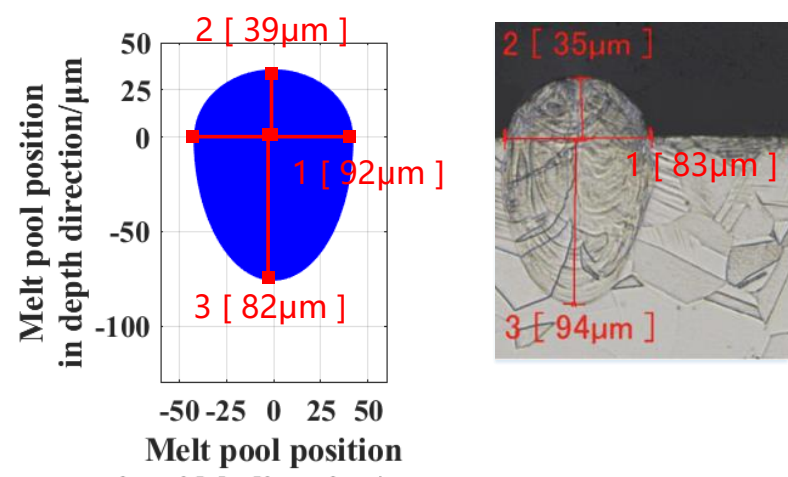

in width direction $/ \mu \mathrm{m}$

Laser power : 300W; Scanning speed : $1.5 \mathrm{~m} / \mathrm{s}$; Layer thickness : $30 \mu \mathrm{m}$; Beam diameter : $54 \mu \mathrm{m}$

(a)

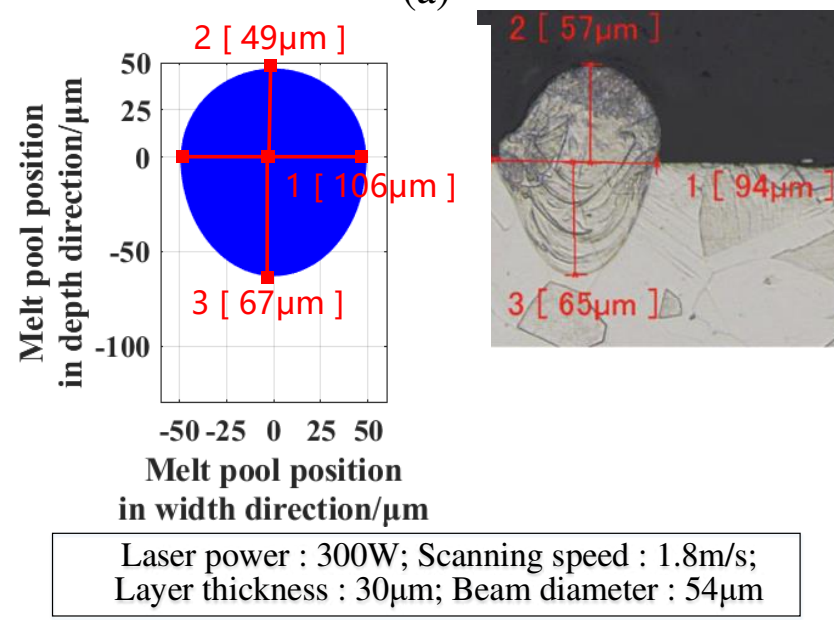

(b)

Fig.12 Comparison of calculated and experimental cross section morphologies (adapted from [32]) of 316L (a) Normal morphology (b) Slightly balling (All graphs are presented at the same size scale)

When relatively larger scanning speed is adopted, the balling phenomenon will be more likely to occur, which is consistent with the conclusion of reference [37]. Results show that the proposed calculation model can effectively assess the normal and defective melt pool cross section morphologies for IN718, TC4 and 316L material. Unfortunately, the range of process parameters of normal and balling melt pool may overlap, which aggravates the difficulty for prediction of melt pool shape.

Due to existence of some unstable phenomena such as balling, evaporation, splashing, as well as surface tension and recoil force, which have a greater impact on the height, depth and length of melt pool, but a much smaller impact on the melt pool width. These unstable factors will reduce the prediction accuracy of the proposed 
calculation model. In addition, the calculation model is based on some assumptions, such as the assumptions of melt pool shape, steady-state melt pool temperature and some constant material attributes, which will bring about loss of the calculation accuracy of the calculation model.

\section{Discussion}

The effectiveness of the proposed model has been validated in Section 3. And some significant thresholds and the uncertainty of the proposed model are pointed out and discussed here.

The thresholds of melting degree index will change with different materials and/or process parameters. Thus the boundary thresholds of different melting degrees are selected according to the summarized empirical Formulae (5)-(8), wherein the parameters $\chi^{m}, h_{\mathrm{sl}}, C, a, T_{b}$ and $T_{m}$ mainly take into account the influence of different material types while other factors like $v, D, L_{t}$ and $T_{o}$ consider the effect of different process parameters. The trend of selected thresholds is also consistent with literature [38]. And the coefficients of $\chi^{m}, \Pi_{1}^{m}$ and $\Pi_{2}^{m}$ could be updated based on more experimental observations.

The results in Fig.9 show that the model has relatively poor classification ability for balling melt pool. This is due to that the balling phenomenon is stochastic and uncertain. We adopt the ratio of melt pool height to layer thickness to identify the balling effect. However, balling phenomenon is not obvious in some situations, which are not counted into balling type in our study, while the lower percentage of balling was used in literature [12]. Moreover, the range of process parameters between normal and balling melt pool might also overlap.

It has been assumed that the shape of single melt pool in single track for SLM process was composed of dual semi-ellipsoids in this approach. However, the actual morphology of melt pool is more complex. Hence this hypothesis will give rise to certain errors during the melt pool reconsitution. In the real forming process of SLM, the powder layer may fluctuate, and the thickness of powder layer might be uneven. Laser beam diameter of the machine may not be constant, perhaps there are somewhat dynamic changes or adjustments. The denudation and random spatter of the powder also affect the melt pool morphology, which is also the error source of the proposed model.

\section{Conclusion}

Overall, a relevance computational model of process factors and melt pool structure is proposed for SLM process. The mathematics correlations between melt pool geometries and process parameters are constructed through the proposed model. In this model, process parameters such as laser beam power, scanning speed, layer thickness and laser beam diameter, etc. are involved as input variables, while melt pool 
geometries are output variables. The proposed model is available for commonly-used process parameter scope and could effectively predict the normal and defective melt pool morphology under different melt pool modes and melting states for distinct materials and machines through process parameters, which can reduce experimental trial-and-error costs. As the model involve more physical principles compared with existing empirical models, it has better calculation accuracy. As the model reveals the mathematical representation between process parameters and melt pool structure directly, it has faster calculation speed compared with finite element models. Furthermore, the model is able to be applied in melt pool classification and prediction, laying the foundation for geometric simulation research of SLM object which is successively shaped melt-pool by melt-pool (block-by-block).

Currently, melt pool morphologies of three kinds of materials have been researched, and more materials should be explored later. The variation principles of material parameters under distinct process conditions would be investigated to elevate the accuracy of the calculation model. The forming characteristics of melt pool morphologies between adjacent scanning tracks and layers and the effect of melt pool morphology on the final forming geometry of SLM object would be covered in future work.

\section{Appendix A Material properties for IN718, TC4 and 316L}

Table 3 Material parameters of IN718, TC4 and 316L for calculation

\begin{tabular}{ccccc}
\hline \multirow{2}{*}{ Parameter } & Symbol & \multicolumn{3}{c}{ Value } \\
\cline { 3 - 5 } & & $\mathrm{IN} 718$ & $\mathrm{TC} 4$ & $316 \mathrm{~L}$ \\
\hline Thermal diffusivity & $a\left(\mathrm{~m}^{2} / \mathrm{s}\right)$ & $5.95 \mathrm{e}^{-6}[39]$ & $1.07 \mathrm{e}^{-5}[30]$ & $6.37 \mathrm{e}^{-6}[3]$ \\
Specific heat capacity & $C(\mathrm{~J} /(\mathrm{kgK}))$ & 543.5 & 817.5 & 725 \\
Liquid specific heat capacity & $C_{l}(\mathrm{~J} /(\mathrm{kgK}))$ & $720[40]$ & $872[41]$ & $770[3]$ \\
Solid specific heat capacity & $C_{s}(\mathrm{~J} /(\mathrm{kgK}))$ & $435[40]$ & $763[41]$ & $680[3]$ \\
Latent heat of fusion & $h_{\mathrm{sl}}(\mathrm{J} / \mathrm{kg})$ & $2.1 \mathrm{e}^{5}$ & $3.65 \mathrm{e}^{5}$ & $2.7 \mathrm{e}^{5}$ \\
Thermal conductivity & $k(\mathrm{~W} /(\mathrm{mK}))$ & $24.1[42]$ & $21[42]$ & $36[42]$ \\
Boiling temperature & $T_{b}(\mathrm{~K})$ & $3111[40]$ & $3300[3]$ & $3273[15]$ \\
Melting temperature & $T_{m}(\mathrm{~K})$ & $1609[42]$ & $1928[30]$ & $1700[3]$ \\
Convection coefficient & $\alpha_{g}\left(\mathrm{~W}\left(\mathrm{~m}^{2} \mathrm{~K}\right)\right)$ & $8[43]$ & $10[44]$ & $100[45]$ \\
Thermal radiation coefficient & $\varepsilon$ & $0.32[40]$ & $0.43[8]$ & $0.35[45]$ \\
Density & $\rho\left(\mathrm{kg}^{5} / \mathrm{m}^{3}\right)$ & $7451[39]$ & $4000[41]$ & $7800[42]$ \\
Powder compaction rate & $\rho_{p} / \rho_{s}$ & $0.6[11]$ & $0.6[11]$ & $0.6[11]$ \\
Stefan-Boltzmann coefficient & $\sigma\left(\mathrm{W} /\left(\mathrm{m}^{2} \mathrm{~K}^{4}\right)\right)$ & $5.67 \mathrm{e}^{-8}$ & $5.67 \mathrm{e}^{-8}$ & $5.67 \mathrm{e}^{-8}$ \\
\hline
\end{tabular}




\section{Appendix B Adopted energy absorptivity under different}

\section{machines and process conditions for IN718, TC4 and 316L}

Table 4 Adopted energy absorptivity under different machines and process conditions for IN718

\begin{tabular}{|c|c|c|c|c|c|c|}
\hline Machine & $\begin{array}{l}\text { Laser } \\
\text { power }\end{array}$ & $\begin{array}{c}\text { Scanning } \\
\text { speed }\end{array}$ & $\begin{array}{c}\text { Laser } \\
\text { diameter }\end{array}$ & $\begin{array}{c}\text { Layer } \\
\text { thickness }\end{array}$ & $\begin{array}{c}\text { Powder } \\
\text { absorptivity }\end{array}$ & $\begin{array}{c}\text { Solid } \\
\text { absorptivity }\end{array}$ \\
\hline \multirow{12}{*}{$\begin{array}{c}\text { EOS M280 } \\
{[27]}\end{array}$} & 300 & 0.2 & 100 & 40 & 0.95 & 0.15 \\
\hline & 200 & 0.2 & 100 & 40 & 0.95 & 0.15 \\
\hline & 150 & 0.2 & 100 & 40 & 0.95 & 0.15 \\
\hline & 100 & 0.2 & 100 & 40 & 0.95 & 0.15 \\
\hline & 300 & 0.7 & 100 & 40 & 0.8 & 0.28 \\
\hline & 200 & 0.7 & 100 & 40 & 0.8 & 0.28 \\
\hline & 300 & 1.2 & 100 & 40 & 0.8 & 0.28 \\
\hline & 150 & 0.7 & 100 & 40 & 0.3 & 0.28 \\
\hline & 200 & 1.2 & 100 & 40 & 0.3 & 0.28 \\
\hline & 300 & 2.2 & 100 & 40 & 0.3 & 0.28 \\
\hline & 150 & 1.2 & 100 & 40 & 0.3 & 0.28 \\
\hline & 300 & 2.5 & 100 & 40 & 0.3 & 0.28 \\
\hline \multirow{22}{*}{$\begin{array}{c}\text { EOS M290 } \\
\text { [11] }\end{array}$} & 316 & 0.4 & 100 & 40 & 0.95 & 0.28 \\
\hline & 152 & 0.2 & 100 & 40 & 0.95 & 0.28 \\
\hline & 123 & 0.2 & 100 & 40 & 0.95 & 0.28 \\
\hline & 241 & 0.4 & 100 & 40 & 0.95 & 0.28 \\
\hline & 339 & 0.6 & 100 & 40 & 0.95 & 0.28 \\
\hline & 111 & 0.2 & 100 & 40 & 0.95 & 0.28 \\
\hline & 339 & 0.8 & 100 & 40 & 0.95 & 0.15 \\
\hline & 254 & 0.6 & 100 & 40 & 0.95 & 0.15 \\
\hline & 168 & 0.4 & 100 & 40 & 0.95 & 0.15 \\
\hline & 250 & 0.6 & 100 & 40 & 0.95 & 0.15 \\
\hline & 165 & 0.4 & 100 & 40 & 0.95 & 0.15 \\
\hline & 127 & 0.4 & 100 & 40 & 0.7 & 0.28 \\
\hline & 306 & 1 & 100 & 40 & 0.7 & 0.28 \\
\hline & 281 & 0.96 & 100 & 40 & 0.7 & 0.28 \\
\hline & 233 & 0.8 & 100 & 40 & 0.7 & 0.28 \\
\hline & 157 & 0.6 & 100 & 40 & 0.7 & 0.28 \\
\hline & 100 & 0.4 & 100 & 40 & 0.7 & 0.28 \\
\hline & 139 & 0.6 & 100 & 40 & 0.7 & 0.28 \\
\hline & 179 & 0.8 & 100 & 40 & 0.7 & 0.28 \\
\hline & 200 & 0.96 & 100 & 40 & 0.7 & 0.28 \\
\hline & 206 & 1 & 100 & 40 & 0.7 & 0.28 \\
\hline & & & $26 / 3$ & & & \\
\hline
\end{tabular}




\begin{tabular}{cllllll} 
& 234 & 1.2 & 100 & 40 & 0.7 & 0.28 \\
& 154 & 1 & 100 & 40 & 0.3 & 0.28 \\
& 181 & 1.2 & 100 & 40 & 0.3 & 0.28 \\
& 144 & 0.96 & 100 & 40 & 0.3 & 0.28 \\
& 119 & 0.8 & 100 & 40 & 0.3 & 0.28 \\
& 103 & 0.96 & 100 & 40 & 0.3 & 0.28 \\
\hline Concept & 107 & 1 & 100 & 40 & 0.3 & 0.28 \\
M1 [28] & 180 & 0.4 & 100 & 40 & 0.7 & 0.28 \\
\cline { 1 - 3 } Tongtai & 180 & 0.6 & 100 & 40 & 0.7 & 0.28 \\
AM250 & 180 & 0.8 & 100 & 40 & 0.7 & 0.28 \\
[29] & 180 & 0.4 & 54 & 40 & 0.9 & 0.1 \\
\hline
\end{tabular}

Table 5 Adopted energy absorptivity under different machines and process conditions for TC4

\begin{tabular}{|c|c|c|c|c|c|c|}
\hline Machine & $\begin{array}{l}\text { Laser } \\
\text { power }\end{array}$ & $\begin{array}{c}\text { Scanning } \\
\text { speed }\end{array}$ & $\begin{array}{c}\text { Laser } \\
\text { diameter }\end{array}$ & $\begin{array}{c}\text { Layer } \\
\text { thickness }\end{array}$ & $\begin{array}{c}\text { Powder } \\
\text { absorptivity }\end{array}$ & $\begin{array}{c}\text { Solid } \\
\text { absorptivity }\end{array}$ \\
\hline \multirow{19}{*}{$\begin{array}{c}\text { Custom } \\
{[30]}\end{array}$} & 200 & 0.1 & 100 & 20 & 0.95 & 0.15 \\
\hline & 200 & 0.2 & 100 & 20 & 0.7 & 0.28 \\
\hline & 200 & 0.3 & 100 & 20 & 0.7 & 0.28 \\
\hline & 500 & 0.4 & 100 & 40 & 0.4 & 0.28 \\
\hline & 400 & 0.4 & 100 & 40 & 0.4 & 0.28 \\
\hline & 200 & 0.4 & 100 & 20 & 0.7 & 0.28 \\
\hline & 200 & 0.3 & 100 & 30 & 0.7 & 0.28 \\
\hline & 200 & 0.5 & 100 & 20 & 0.7 & 0.28 \\
\hline & 300 & 0.4 & 100 & 40 & 0.7 & 0.28 \\
\hline & 200 & 0.3 & 100 & 40 & 0.5 & 0.28 \\
\hline & 200 & 0.6 & 100 & 20 & 0.5 & 0.28 \\
\hline & 200 & 0.7 & 100 & 20 & 0.5 & 0.28 \\
\hline & 200 & 0.3 & 100 & 50 & 0.5 & 0.28 \\
\hline & 200 & 0.4 & 100 & 40 & 0.5 & 0.28 \\
\hline & 200 & 0.8 & 100 & 20 & 0.5 & 0.28 \\
\hline & 200 & 0.3 & 100 & 60 & 0.5 & 0.28 \\
\hline & 200 & 0.9 & 100 & 20 & 0.5 & 0.28 \\
\hline & 200 & 1 & 100 & 20 & 0.5 & 0.28 \\
\hline & 100 & 0.4 & 100 & 40 & 0.2 & 0.28 \\
\hline & 50 & 0.1 & 70 & 0 & 0.7 & 0.28 \\
\hline IPG & 30 & 0.1 & 70 & 0 & 0.5 & 0.28 \\
\hline Photonics & 50 & 0.2 & 70 & 0 & 0.5 & 0.28 \\
\hline \multirow[t]{3}{*}{ [31] } & 20 & 0.1 & 70 & 0 & 0.5 & 0.28 \\
\hline & 50 & 0.3 & 70 & 0 & 0.5 & 0.28 \\
\hline & & & $27 / 32$ & & & \\
\hline
\end{tabular}




\begin{tabular}{llllll}
30 & 0.2 & 70 & 0 & 0.5 & 0.28 \\
30 & 0.3 & 70 & 0 & 0.5 & 0.28 \\
20 & 0.2 & 70 & 0 & 0.5 & 0.28 \\
20 & 0.3 & 70 & 0 & 0.5 & 0.28 \\
\hline
\end{tabular}

Table 6 Adopted energy absorptivity under different machines and process conditions for $316 \mathrm{~L}$

\begin{tabular}{|c|c|c|c|c|c|c|}
\hline Machine & $\begin{array}{l}\text { Laser } \\
\text { power }\end{array}$ & $\begin{array}{c}\text { Scanning } \\
\text { speed }\end{array}$ & $\begin{array}{c}\text { Laser } \\
\text { diameter }\end{array}$ & $\begin{array}{c}\text { Layer } \\
\text { thickness }\end{array}$ & $\begin{array}{c}\text { Powder } \\
\text { absorptivity }\end{array}$ & $\begin{array}{c}\text { Solid } \\
\text { absorptivity }\end{array}$ \\
\hline \multirow{26}{*}{$\begin{array}{c}\text { Custom } \\
\text { [15] }\end{array}$} & 400 & 0.4 & 55 & 75 & 0.95 & 0.28 \\
\hline & 300 & 0.3 & 55 & 75 & 0.95 & 0.28 \\
\hline & 200 & 0.2 & 55 & 75 & 0.95 & 0.28 \\
\hline & 500 & 0.75 & 55 & 75 & 0.95 & 0.28 \\
\hline & 400 & 0.6 & 55 & 75 & 0.95 & 0.28 \\
\hline & 300 & 0.45 & 55 & 75 & 0.95 & 0.28 \\
\hline & 200 & 0.3 & 55 & 75 & 0.95 & 0.28 \\
\hline & 100 & 0.15 & 55 & 75 & 0.95 & 0.28 \\
\hline & 500 & 1 & 55 & 75 & 0.95 & 0.28 \\
\hline & 400 & 0.8 & 55 & 75 & 0.95 & 0.28 \\
\hline & 300 & 0.6 & 55 & 75 & 0.95 & 0.28 \\
\hline & 200 & 0.4 & 55 & 75 & 0.95 & 0.28 \\
\hline & 100 & 0.2 & 55 & 75 & 0.95 & 0.28 \\
\hline & 500 & 1.25 & 55 & 75 & 0.95 & 0.1 \\
\hline & 400 & 1 & 55 & 75 & 0.95 & 0.1 \\
\hline & 300 & 0.75 & 55 & 75 & 0.95 & 0.1 \\
\hline & 200 & 0.5 & 55 & 75 & 0.95 & 0.1 \\
\hline & 100 & 0.25 & 55 & 75 & 0.95 & 0.1 \\
\hline & 500 & 1.5 & 55 & 75 & 0.95 & 0.1 \\
\hline & 400 & 1.2 & 55 & 75 & 0.95 & 0.1 \\
\hline & 300 & 0.9 & 55 & 75 & 0.95 & 0.1 \\
\hline & 200 & 0.6 & 55 & 75 & 0.7 & 0.1 \\
\hline & 100 & 0.3 & 55 & 75 & 0.7 & 0.1 \\
\hline & 400 & 2 & 55 & 75 & 0.7 & 0.1 \\
\hline & 300 & 1.5 & 55 & 75 & 0.7 & 0.1 \\
\hline & 200 & 1 & 55 & 75 & 0.7 & 0.1 \\
\hline \multirow{6}{*}{$\begin{array}{l}\text { Concept } \\
\text { M2 [32] }\end{array}$} & 200 & 0.5 & 54 & 30 & 0.95 & 0.28 \\
\hline & 300 & 0.8 & 54 & 30 & 0.95 & 0.28 \\
\hline & 400 & 1.2 & 54 & 30 & 0.95 & 0.28 \\
\hline & 150 & 0.5 & 54 & 30 & 0.95 & 0.15 \\
\hline & 400 & 1.5 & 54 & 30 & 0.95 & 0.15 \\
\hline & 300 & 1.2 & 54 & 30 & 0.95 & 0.15 \\
\hline
\end{tabular}




\begin{tabular}{|c|c|c|c|c|c|c|}
\hline & 200 & 0.8 & 54 & 30 & 0.95 & 0.15 \\
\hline & 400 & 1.8 & 54 & 30 & 0.95 & 0.15 \\
\hline & 300 & 1.5 & 54 & 30 & 0.95 & 0.15 \\
\hline & 150 & 0.8 & 54 & 30 & 0.95 & 0.15 \\
\hline & 300 & 1.8 & 54 & 30 & 0.95 & 0.1 \\
\hline & 200 & 1.2 & 54 & 30 & 0.95 & 0.1 \\
\hline & 200 & 1.5 & 54 & 30 & 0.7 & 0.15 \\
\hline & 150 & 1.2 & 54 & 30 & 0.7 & 0.28 \\
\hline \multirow{4}{*}{ Phenix [33] } & 50 & 0.12 & 100 & 50 & 0.7 & 0.1 \\
\hline & 50 & 0.16 & 100 & 50 & 0.7 & 0.1 \\
\hline & 50 & 0.2 & 100 & 50 & 0.7 & 0.1 \\
\hline & 50 & 0.24 & 100 & 50 & 0.7 & 0.1 \\
\hline
\end{tabular}

Acknowledgment This work is supported by the National Natural Science Foundation of China (Grant No. 52005021). The authors gratefully acknowledge their financial support.

Funding This research is funded by the National Natural Science Foundation of China Grant Number 52005021.

Availability of data and material Not applicable.

Code availability Not applicable.

Authors' contributions Kai Guo: conceptualization, methodology, investigation, visualization, writing — original draft. Lihong Qiao: conceptualization, methodology, writing — review and editing, supervision. Zhicheng Huang: methodology, writingreview and editing, supervision, project administration. Nabil Anwer: writing - review and editing, supervision. Yuda Cao: writing—review and editing.

\section{Declarations}

Competing interests The authors declare no competing interests.

Ethics approval Not applicable.

Consent to participate Not applicable.

Consent for publication All the authors agree with the publication. 


\section{References}

[1] King WE, Barth HD, Castillo VM et al (2014) Observation of keyhole-mode laser melting in laser powder-bed fusion additive manufacturing. J Mater Process Tech 214(12):2915-2925. https://doi.org/10.1016/j.jmatprotec.2014.06.005

[2] Bikas H, Stavropoulos P, Chryssolouris G (2016) Additive manufacturing methods and modelling approaches: a critical review. Int J Adv Manuf Tech 83:389-405. https://doi.org/10.1007/s00170-015-7576-2

[3] Liu B, Fang G, Lei L (2021) An analytical model for rapid predicting molten pool geometry of selective laser melting (SLM). Appl Math Model 92:505-524. https://doi.org/10.1016/j.apm.2020.11.027

[4] Chen D, Wang P, Pan R et al (2021) Research on in situ monitoring of selective laser melting: a state of the art review. Int J Adv Manuf Tech 113:3121-3138. https://doi.org/10.1007/s00170-020-06432-1

[5] Han X, Zhu H, Nie X et al (2018) Investigation on selective laser melting AlSi10Mg cellular lattice strut: molten pool morphology, surface roughness and dimensional accuracy. Materials 11(3):392. https://doi.org/10.3390/ma11030392

[6] Gu D, Shi X, Poprawe R et al (2021) Material-structure-performance integrated laser-metal additive manufacturing. Science $372 \quad$ (6545). https://doi.org/10.1126/science.abg1487

[7] Seede R, Shoukr D, Zhang B et al (2020) An ultra-high strength martensitic steel fabricated using selective laser melting additive manufacturing: Densification, microstructure, and mechanical properties. Acta Mater 186:199-214. https://doi.org/10.1016/j.actamat.2019.12.037

[8] Wang Q, Michaleris PP, Nassar AR et al (2020) Model-based feedforward control of laser powder bed fusion additive manufacturing. Addit Manuf 31:100985. https://doi.org/10.1016/j.addma.2019.100985

[9] Doumanidis C, Kwak YM (2001) Geometry modeling and control by infrared and laser sensing in thermal manufacturing with material deposition. J Manuf Sci Eng 123(1):45-52. https://doi.org/10.1115/1.1344898

[10] Wang Q (2019) A control-oriented model for melt-pool volume in laser powder bed fusion additive manufacturing. Dynamic Systems and Control Conference, American Society of Mechanical Engineers 59148:V001T10A002. https://asmedigitalcollection.asme.org/DSCC/proceedings/DSCC2019/59148/V00 1T10A002/1070481

[11] Scime L, Beuth J (2019) Melt pool geometry and morphology variability for the Inconel 718 alloy in a laser powder bed fusion additive manufacturing process. Addit Manuf 29:100830. https://doi.org/10.1016/j.addma.2019.100830

[12] Scime L, Beuth J (2019) Using machine learning to identify in-situ melt pool signatures indicative of flaw formation in a laser powder bed fusion additive manufacturing process. Addit Manuf 25:151-165. https://doi.org/10.1016/j.addma.2018.11.010

[13]Papadakis L, Loizou A, Risse J et al (2014) A computational reduction model for appraising structural effects in selective laser melting manufacturing: a methodical model reduction proposed for time-efficient finite element analysis of larger components in Selective Laser Melting. Virtual Phys Prototyp 9(1):17-25. https://doi.org/10.1080/17452759.2013.868005

[14]Francis ZR (2017) The effects of laser and electron beam spot size in additive manufacturing processes. Dissertation, Carnegie Mellon University 
[15]Bertoli US, Wolfer AJ, Matthews MJ et al (2017) On the limitations of volumetric energy density as a design parameter for selective laser melting. Mater Design 113: 331-340. https://doi.org/10.1016/j.matdes.2016.10.037

[16]Rubenchik AM, King WE, Wu SS (2018) Scaling laws for the additive manufacturing. J Mater Process Tech 257:234-243. https://doi.org/10.1016/j.jmatprotec.2018.02.034

[17]Mirkoohi E, Sievers DE, Garmestani H et al (2019) Three-dimensional semielliptical modeling of melt pool geometry considering hatch spacing and time spacing in metal additive manufacturing. J Manuf Process 45:532-543. https://doi.org/10.1016/j.jmapro.2019.07.028

[18] Tang M, Pistorius PC, Beuth JL (2017) Prediction of lack-of-fusion porosity for powder bed fusion. Addit Manuf 14:39-48. https://doi.org/10.1016/j.addma.2016.12.001

[19]Promoppatum P, Yao SC, Pistorius PC et al (2017) A comprehensive comparison of the analytical and numerical prediction of the thermal history and solidification microstructure of Inconel 718 products made by laser powder-bed fusion. Engineering 3(5):685-694. https://doi.org/10.1016/J.ENG.2017.05.023

[20]Eagar TW, Tsai NS (1983) Temperature fields produced by traveling distributed heat sources. Weld J 62(12):346-355

[21] Mukherjee T, Zuback JS, De A et al (2016) Printability of alloys for additive manufacturing. Sci Rep 6(1):1-8. https://doi.org/10.1038/srep19717

[22] Shrestha S, Chou K (2021) An investigation into melting modes in selective laser melting of Inconel 625 powder: single track geometry and porosity. Int J Adv Manuf Tech 114:3255-3267. https://doi.org/10.1007/s00170-021-07105-3

[23]Foroozmehr A, Badrossamay M, Foroozmehr E et al (2016) Finite element simulation of selective laser melting process considering optical penetration depth of laser in powder bed. Mater Design 89:255-263. https://doi.org/10.1016/j.matdes.2015.10.002

[24] Cannon JR (1984) The one-dimensional heat equation. Cambridge University Press, Cambridge

[25] Gladush GG, Smurov I (2011) Physics of laser materials processing: theory and experiment. Springer Science \& Business Media

[26] Philo AM, Mehraban S, Holmes M et al (2019) A pragmatic continuum level model for the prediction of the onset of keyholing in laser powder bed fusion. Int $\mathrm{J} \mathrm{Adv}$ Manuf Tech 101(1):697-714. https://doi.org/10.1007/s00170-018-2770-7

[27] Andreotta R, Ladani L, Brindley W (2017) Finite element simulation of laser additive melting and solidification of Inconel 718 with experimentally tested thermal properties. Finite Elem Anal Des 135:36-43. https://doi.org/10.1016/j.finel.2017.07.002

[28]Cheng B, Lydon J, Cooper K et al (2018) Melt pool sensing and size analysis in laser powder-bed metal additive manufacturing. J Manuf Process 32:744-753. https://doi.org/10.1016/j.jmapro.2018.04.002

[29]Le TN, Lo YL, Lin ZH (2020) Numerical simulation and experimental validation of melting and solidification process in selective laser melting of IN718 alloy. Addit Manuf 36:101519. https://doi.org/10.1016/j.addma.2020.101519

[30] Yang J, Han J, Yu H et al (2016) Role of molten pool mode on formability, microstructure and mechanical properties of selective laser melted Ti-6Al-4V alloy. Mater Design 110:558-570. https://doi.org/10.1016/j.matdes.2016.08.036

[31] Yadroitsev I, Krakhmalev P, Yadroitsava I (2014) Selective laser melting of 
Ti6Al4V alloy for biomedical applications: Temperature monitoring and microstructural evolution. J Alloys Compd 583:404-409. https://doi.org/10.1016/j.jallcom.2013.08.183

[32] Kamath C, El-Dasher B, Gallegos GF et al (2014) Density of additivelymanufactured, 316L SS parts using laser powder-bed fusion at powers up to $400 \mathrm{~W}$. Int J Adv Manuf Tech 74(1):65-78. https://doi.org/10.1007/s00170-014-5954-9

[33] Gusarov AV, Yadroitsev I, Bertrand P et al (2009) Model of radiation and heat transfer in laser-powder interaction zone at selective laser melting. J Heat Transfer 131(7):072101. https://doi.org/10.1115/1.3109245

[34]Balbaa MA, Ghasemi A, Fereiduni E et al (2021) Role of powder particle size on laser powder bed fusion processability of AlSi10Mg alloy. Addit Manuf 37:101630. https://doi.org/10.1016/j.addma.2020.101630

[35] Khairallah SA, Martin AA, Lee JR et al (2020) Controlling interdependent mesonanosecond dynamics and defect generation in metal 3D printing. Science 368(6491):660-665. https://doi.org/10.1126/science.aay7830

[36] Tolochko NK, Khlopkov YV, Mozzharov SE et al (2000) Absorptance of powder materials suitable for laser sintering. Rapid Prototyp J 6(3):155-160. https://doi.org/10.1108/13552540010337029

[37] Yadroitsev I, Gusarov A, Yadroitsava I et al (2010) Single track formation in selective laser melting of metal powders. J Mater Process Tech 210(12):1624-1631. https://doi.org/10.1016/j.jmatprotec.2010.05.010

[38] Yap CY, Chua CK, Dong ZL (2016) An effective analytical model of selective laser melting. Virtual Phys Prototy 11(1):21-26. http://dx.doi.org/10.1080/17452759.2015.1133217

[39]Plotkowski A, Kirka MM, Babu SS (2017) Verification and validation of a rapid heat transfer calculation methodology for transient melt pool solidification conditions in powder bed metal additive manufacturing. Addit Manuf 18:256-268. https://doi.org/10.1016/j.addma.2017.10.017

[40]Zhao Y, Koizumi Y, Aoyagi K et al (2019) Molten pool behavior and effect of fluid flow on solidification conditions in selective electron beam melting (SEBM) of a biomedical Co-Cr-Mo alloy. Addit Manuf 26:202-214. https://doi.org/10.1016/j.addma.2018.12.002

[41] Ge W, Han S, Fang Y et al (2017) Mechanism of surface morphology in electron beam melting of Ti6A14V based on computational flow patterns. Appl Surf Sci 419:150-158. http://dx.doi.org/10.1016/j.apsusc.2017.05.033

[42] Wei HL, Mukherjee T, Zhang W et al (2021) Mechanistic models for additive manufacturing of metallic components. Prog Mater Sci 116: 100703. https://doi.org/10.1016/j.pmatsci.2020.100703

[43]Dunbar AJ, Denlinger ER, Gouge MF et al (2016) Experimental validation of finite element modeling for laser powder bed fusion deformation. Addit Manuf 12:108120. http://dx.doi.org/10.1016/j.addma.2016.08.003

[44]Dai D, Gu D, Ge Q et al (2020) Mesoscopic study of thermal behavior, fluid dynamics and surface morphology during selective laser melting of Ti-based $\begin{array}{lllll}\text { composites. } & \text { Comp } & \text { Mater } & \text { Sci } & \text { 177:109598. }\end{array}$ https://doi.org/10.1016/j.commatsci.2020.109598

[45] Waqar S, Sun Q, Liu J et al (2021) Numerical investigation of thermal behavior and melt pool morphology in multi-track multi-layer selective laser melting of the 316L steel. Int J Adv Manuf Tech 112(3):879-895. https://doi.org/10.1007/s00170020-06360-0 